DAUDNINE

\section{$\mathrm{D}$}

I A L

UMR 225 IRD - Paris-Dauphine

Institut de recherche pour le développement

\title{
The Labor Market Effects of Skill-
} biased Technological Change in Malaysia

\section{Björn NILSSON \\ Mohamed Ali MAROUANI}




\title{
THE LABOR MARKET EFFECTS OF SKILL-BIASED TECHNOLOGICAL CHANGE IN MALAYSIA ${ }^{1}$
}

\author{
Mohamed Ali Marouani \\ UMR «Développement et Société », \\ IEDES / Université Paris1-Panthéon-Sorbonne, \\ PSL, Université Paris-Dauphine, \\ LEDa, IRD UMR DIAL, 75016 Paris, France et ERF \\ marouani@univ-paris1.fr
}

\author{
Björn Nilsson \\ PSL, Université Paris-Dauphine, LEDa, \\ LEDa, UMR DIAL, 75016 Paris, France \\ IRD, UMR DIAL, 75010 Paris \\ nilsson@dial.prd.fr
}

\section{Document de travail UMR DIAL}

Décembre 2014

\begin{abstract}
During the last half-century, the evolution of educational attainment among Malaysians has been spectacular, and current enrollment rates suggest this progression will continue, albeit at a slower pace. Such a transformation of the educational attainment of labor should bring about macroeconomic effects such as wage compression, sectoral shifts and/or high skill un- employment, unless compensatory mechanisms exist. This article examines the impact of this evolution using a dynamic general equilibrium model applied to Malaysia. We argue that skill biased technological change occurred in Malaysia in recent years, and permitted unemployment figures to remain low and skill premia not to sink, despite the shift in skill structure. We run a retrospective simulation, looking at how unemployment and wages would have reacted had skill biased technological change not been prevalent. We also simulate the effects of a restriction in the supply of education to understand the impact of recent educational policy in Malaysia. The results are fed to a microdata set using a microaccounting technique, addressing distributional concerns. Our results show that the reduction in wage inequalities could have been substan- tially more important had skill biased technological change not been present. Furthermore, they suggest that the open-door higher education policy has contributed heavily to a reduction in wage inequalities.
\end{abstract}

Key words: Skills acquisition, CGE, Education and the Labor Market, Technological change.

\section{Résumé}

Depuis plusieurs décennies, l'évolution des dotations éducationnelles des malaisiens a été spectaculaire, et les taux de scolarisation actuels indiquent que cette tendance va se poursuivre. Une telle transformation des dotations éducationnelles des travailleurs devraient engendrer des effets macroéconomiques tels qu'une compression des salaires, des glissements sectoriels et une hausse du chômage des qualifiés, en l'absence de mécanismes compensatoires. Cet article examine l'impact d'une telle évolution en utilisant un modèle d'équilibre général dynamique appliqué à la Malaisie. Nous affirmons qu'un progrès technique biaisé en faveur du travail qualifié a été présent en Malaisie dans la période récente, permettant des taux de chômage des qualifiés à rester bas et les rapports salariaux à ne pas baisser, malgré l'évolution de la structure des dotations. Nous faisons une simulation rétrospective, examinant les effets potentiels sur le chômage et les salaires en l'absence du biais du progrès technique. Nous simulons également une restriction de l'offre d'éducation pour comprendre l'impact de la politique de formation récente en Malaisie. Les résultats sont injectés dans une base de microdonnées utilisant une technique de microsimulation. Les résultats montrent que la réduction des inégalités salariales aurait pu être plus forte en l'absence du progrès technique biaisé. Ils suggèrent en outre que la politique éducative généreuse a fortement contribué à une réduction de ces inégalités.

Mots Clés : Acquisition de compétences, EGC, Education et marché du travail, progrès technique

JEL Code : E17, I28, E24, H52, O30, O53

\footnotetext{
This paper is one of the background papers for the report titled "Developing Skills for Innovation and High Income Economy in Malaysia". The authors thank Mr. Amir Omar, Director of Institute of Labor Market Information and Analysis (ILMIA) and his excellent team in the Ministry of Human Resources of Malaysia for their hard work throughout this engagement. Thank you also to the Department of Statistics of Malaysia for assistance with all data related matters, other Government agencies represented in the steering committee for their guidance throughout consultations, and all stakeholders (employers, union representatives and business associations) for their valuable contributions throughout the drafting of this paper The findings, conclusions and views expressed in this paper are entirely those of the authors and should not be attributed to the World Bank, its executive directors and the countries they represent.
} 


\section{Introduction}

Many countries have experienced sharp increases of enrollment in tertiary education in the last decades, with varying economic and social outcomes. The massification of higher education is sometimes a deliberate policy tool, and sometimes the result of a laissez-faire attitude from policy makers facing increased demand for higher education. Should increased educational attainment, especially at the tertiary level, always be encouraged? Will an exogenous increase in the numbers of tertiary educated be followed by increased demand from firms, in some sort of skills-driven structural change? What is the likely impact of increased enrollment on returns to education and on graduate unemployment?

In the presence of an increasing supply of educated labor, labor market outcomes of educated workers are conditional on the evolution of their demand. An underlying issue here is that of the substitutability between labor categories with different educational attainment. Several authors argue (Goldin and Katz 1998; Caselli and Coleman 2006) that this substitutability is imperfect, some countries being better at taking advantage of their skilled workers than others. Caselli and Coleman (2006) argue that countries more abundant in skilled labor will choose technologies best suited to skilled labor, while countries abundant in unskilled labor will choose technologies best suited to unskilled labor, barriers to technology adoption explaining why some countries are unable to make efficient use of their skilled labor. While it would be a stretch to argue that there is consensus on the issue, skill-biased technological change (SBTC) has often been suggested as one of the drivers behind simultaneously rising wage premia and share of skilled workers in the US (Autor, Katz, and Krueger 1998). Empirical evidence has also suggested this is the case in other developed countries. There is some scarce evidence of skill-biased technological change in developing countries (Berman and Machin 2000), but not many country-specific studies have been carried out. To our knowledge, no one has attempted to study skill biased technical change in Malaysia. We choose to study Malaysia since its spectacular increase in educational attainment has not been accompanied by falling wage premia of tertiary graduates.

The other major labor market adjustment to rising relative quantities of skilled labor is increased unemployment of skilled workers. High public investment in education has been shown to increase unemployment in some contexts, high-skilled unemployment sometimes even being higher than that of low and medium-skilled ${ }^{1}$. The MENA region, which has heavily invested in education over four decades ${ }^{2}$ serves as a good example of an unsuccessful absorption of young graduates into the labor market (Marouani 2010; Marouani and Robalino 2012). However, not only do employment figures matter in their own; it is also important to consider the type of employment facing young graduates. The suggested theoretical links between educational accumulation and growth have sometimes been hard to demonstrate empirically. The arguments put forward range from quality of education to a mis-allocation problem. Pritchett (1996) argues that one of the reasons education has not been positive for growth is due to inefficient use of graduates, who end up in low productivity sectors such as State-owned enterprises. This could particularly be the case in those contexts where the State acts as a de facto employer of last resort.

An increase in educational attainment implies two things: first of all, a steadily increasing demand for education. Secondly, that this increased demand has been met by an increased supply, either from the government or from private actors. The question is whether this ex-

\footnotetext{
${ }^{1}$ This is the case for Morocco, (Kabbani and Kothari 2005)

${ }^{2}$ MENA countries spent around 5\% of GDP on education over the period. At similar levels of educational attainment, the MENA region boasts significantly higher unemployment rates of graduates (World Bank 2008) than other emerging regions. The equivalent figure for two groups of Asian and Latin American countries respectively is around $3 \%$
} 
pansion of supply is a deliberate policy choice, or just an expansion to cover what is called the social demand for education. Blaug (1967) reflects on this in an early paper, arguing that the spontaneous increase of educational supply faced with increasing demand could find its origin in a belief that something akin to Say's Law operates in the market for professional manpower, i.e. that supply of skilled labor will create its own demand. Thus planners need not fear increasing educational supply in the sense that labor market constraints are unlikely to operate. The topic is however difficult to apprehend: first of all, without a precise picture of the demand for education, it is impossible to know whether supply has been a constraint or not in the evolution of educational attainment. That is, have all those who wished to go into tertiary education been able to do so? If this is the case, have there not been shadow costs associated with the increase, such as increasing rates of exam failure?

Methodological differences and accuracy problems render educational projection exercises notoriously difficult. Blaug (1967) describes the three major methods of forecasting skill requirements, all relying on a number of assumptions and restrictions. Firstly, manpower-forecasts attempt to project sectoral quantities of skilled labor needed to attain certain GDP targets. They rely on labor-output coefficients and education - occupation matrices that are difficult to estimate. Secondly, social demand methods attempt to project the private demand for education, given fixed direct and indirect costs. Finally, rate of return methods, which are perhaps the most well-known method used by educational planners. Ceteris paribus, the evolution of the rate of return to a certain skill gives an indication of the value the market places on the skill. If this rate is increasing, it means that employers' demand for this particular skill is rising faster than its supply. Rates of return could thus be used by planners as an indicator of skill gaps to be filled. All three methods however have their weaknesses. In particular manpower planning, which has been largely abandoned in academia since its less than desirable track record was unveiled in Blaug and Ahamad (1974).

Glytsos (1990) argues that severe imbalances between supply and demand for certain skills have been a feature of developed and developing countries alike during the 1970s and 1980s, which tends to confirm the mediocre track record of educational planning before and during this period ${ }^{3}$. Interestingly, he argues that these imbalances have not only been a feature of countries with open enrollment policies, i.e. where quantitative restrictions on the number of students do not exist (perhaps due to social concerns such as equality of access), but also in those countries where admission controls are a fact. We contend that a general equilibrium approach to educational planning permits to overcome some of the most obvious drawbacks of the main methods used to project or forecast educational needs. Notably, manpower forecasts and social demand estimates both consider educational dynamics from one side -that of demand in the case of manpower-forecasts, and that of supply in the case of the "social" demand for education. The evolution, however, is determined jointly by supply and demand factors. Furthermore, the demand and supplies are derived using a constant price-hypothesis. A general equilibrium approach permits prices to vary according to relative supply and demand, but also according to productivity and international demand trend differentials. Also, while manpower forecasting and social demand gives target figures, our model permits a simulation of the labor market impacts of educational policy designed to achieve such target figures. Our focus in doing this is on wage premia and unemployment figures.

In this article, we thus study the case of Malaysia in the context of a massification of higher education. We argue that it is thanks to skill biased technological change that expected wage

\footnotetext{
${ }^{3}$ An alternative to educational planning could have been to let the market regulate supply and demand of educational services, requiring that the total cost of educational services is covered by students. Such a system would however have obvious drawbacks in terms of equality of opportunities.
} 
premia have been relatively stable in Malaysia, maintaining a strong social demand for higher education, thereby perpetuating the educational dynamics. The rest of the article is organized as follows. Section 2 describes the Malaysian educational expansion of the last two decades and the accompanying labor market adjustments. Section 3 lays out the various blocks of the model, with a particular emphasis on the accumulation of skilled labor. Section 4 presents the data and the calibration of the model. Section 5 lays out the microaccounting module used to analyze wage inequalities. Section 6 presents the simulations and their results. Section 7 concludes.

\section{The Evolution of Malaysians' Educational Attainment}

Educational attainment in Malaysia has increased remarkably in the last two decades. The two main features of this increase are a big drop in the number of Malaysians with a Primary education or less, coupled with a strong increase in the number of secondary and tertiary educated. The second feature has been a clear policy target for the Malaysian government, desirous to see enrollment rates in higher education of $40 \%$ by 2010 (Guan 2012). The increase in supply of higher education has taken two forms. Firstly, private universities were established in the 1990s (the number of private universities in Malaysia increased from 0 in 1990 to 21 in 2009). Secondly, the number of public universities increased from 7 in 1990 to 20 in 2009. The expansion of tertiary education has not only been a general higher education phenomenon. The creation of Community Colleges and the expansion of Polytechnic establishments have increased enrollment in vocational degrees. Figure 1 shows the evolution of educational attainment of Malaysians over the last two decades, and shows how the share of highly educated Malaysians has risen sharply and continuously since the early 1990s.

Figure 1: Educational distribution of the Malaysian Labor Force, 15-64 years old

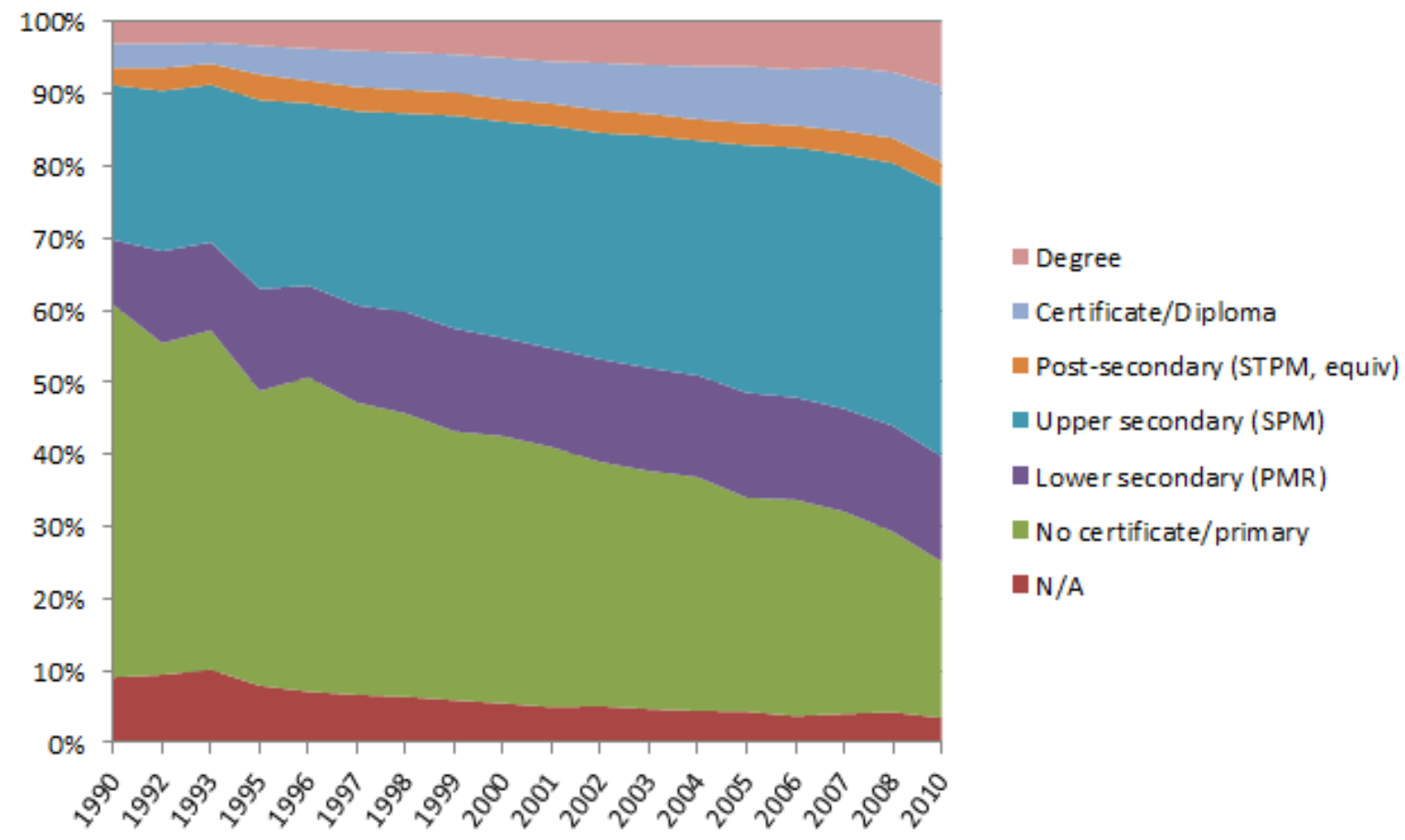

Note: N/A corresponds to individuals who never went to school.

Standard economic theory holds that this important shift in relative quantities should be 
accompanied -ceteris paribus -by a decrease in the wage premium for educated employees. Figure 2 shows that average wages in Malaysia have remained relatively constant between 2007 and $2010^{4}$. An indicator of wage premia can be obtained from studies on returns to education in Malaysia. Chung (2003) looks at the returns to education in Malaysia using a dataset from 1997, and finds that the returns to secondary education are $12 \%$ versus $15.7 \%$ for male and female respectively, while the returns to higher education are $18.1 \%$ and $16.4 \%$. Kenayathulla (2013) recently revisited those figures, using Household Income Survey figures from 2007. She finds evidence of a return to secondary education of $16.5 \%$ and $27.2 \%$ for males and females; the corresponding figures for higher education being $15.5 \%$ and $16.1 \%$. This anecdotal evidence thus suggests the presence of some mechanism favorable to skilled labor during the last two decades in Malaysia.

Fully noting that the concept of skill is a multidimensional and complex one, we choose to define skilled labor categories in terms of various levels of education and fields of study. We hereby ignore any skills acquired in the workplace, or any skill endowments independent of schooling.

Figure 2: Average wage by educational attainment, Malaysian employees (RM)

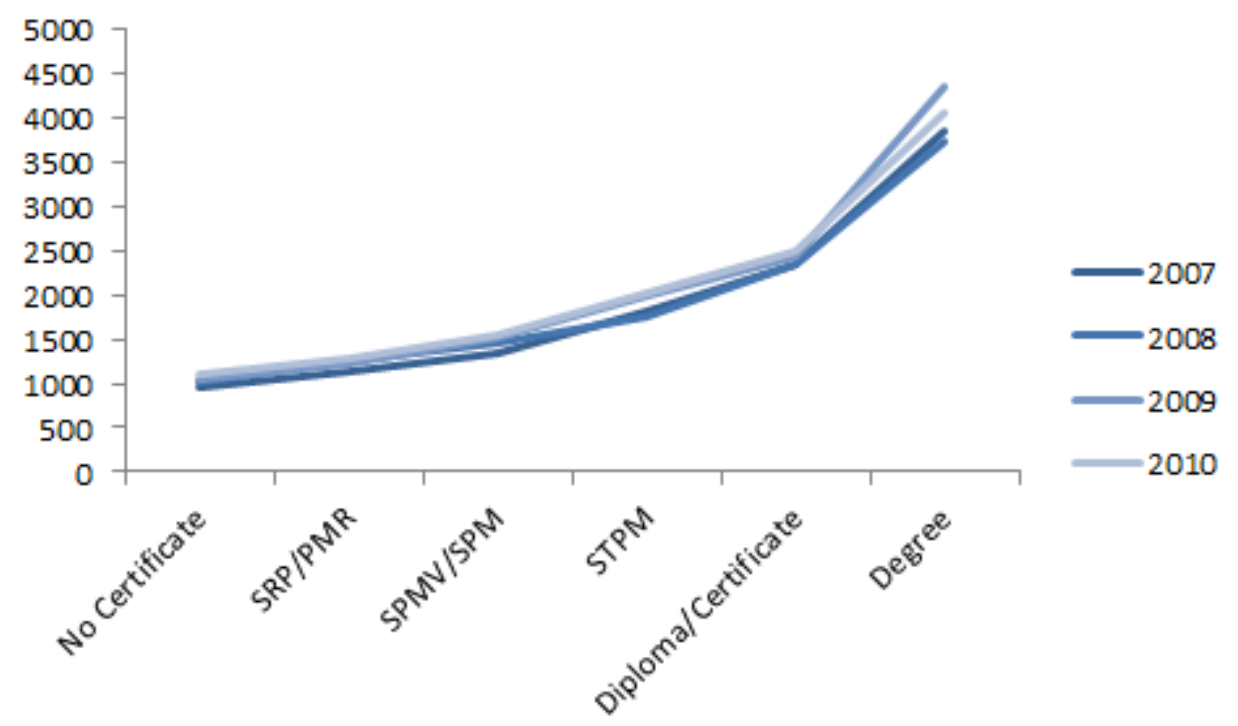

From Figure1, it can be seen that the share of educated Malaysians in the workforce has risen steadily since the early 1990s. The situation is analogous to the US one in the 1980s-1990s, and merits a closer look. At the aggregate level, a standard CES production function yields the following relative wage when profits are maximized (Sanders and Weel 2000):

$$
\omega=\frac{w_{S}}{w_{U}}=\left[\frac{\theta_{S}}{\theta_{U}}\right]^{\rho}\left[\frac{L_{U}}{L_{S}}\right]^{1-\rho}
$$

Where $w_{S}, w_{U}$ and $L_{U}, L_{S}$ are wages and employment of skilled and unskilled workers respetively, $\theta_{S}$ and $\theta_{U}$ the productivity parameters associated with skilled and unskilled labor, and $\frac{1}{1-\rho}$ is the elasticity of substitution between productivity-corrected labor bundles. It thus becomes apparent that in presence of increasing relative quantities of skilled workers, a decrease

\footnotetext{
${ }^{4}$ Unfortunately we do not have wage data from before 2007.
} 
in the wage premium of skilled labor can only be avoided if there is an increase in the relative technological efficiency of this labor category. Figures 1 and 2 would thus suffice to argue for the presence of skill-biased technological change in Malaysia. However, when one considers a sectorally disaggregated production structure, it becomes apparent that sector-biased technological change -if favoring skill-intensive sectors -might in the same fashion increase the demand for skills, counteracting the supply shift and ensuring stable wage premia. Several authors have used translog cost functions to investigate the presence of skill-biased technological change (Machin and Reenen 1998; Autor, Katz, and Krueger 1998; Sanders and Weel 2000). Since we were unable to find R\&D data at the industry level in Malaysia, we do not follow this approach. Table 3 however shows the evolution of industry labor shares and industry skilled labor concentrations between 2007 and 2010. Decomposing the aggregate change in the proportion of skilled labor into changes between and within sectors (Machin and Reenen 1998; Berman, Bound, and Machin 1998) ${ }^{5}$ for Malaysia shows that the lion's share of the upskilling has occurred within industries (74\%) rather than between industries (26\%), which leads us to believe that the simultaneous stability of wage premia and high increase of the skill share are associated with skill-biased technical change, rather than a structural change due to a Stolper-Samuelson effect, or any other industry-biased demand alteration. The same analysis was carried out for a period of 20 years (1990 to 2010) at the 3-digit industry level, with the within component of upskilling being equal to $73 \%$. An analysis of labor at the firm level, using the 2005 and 2010 rounds of the Economic census is carried out in World Bank (Forthcoming), and shows that significant upskilling has occurred at the firm level.

Table 1: Labor Force in 1990, by highest certificate obtained

\begin{tabular}{rrrr}
\hline Degree & Employed & Unemployed & Total Labor Force \\
\hline SRP/PMR & $92.7 \%$ & $7.3 \%$ & $100.0 \%$ \\
SPMV & $89.6 \%$ & $10.4 \%$ & $100.0 \%$ \\
SPM & $93.4 \%$ & $6.6 \%$ & $100.0 \%$ \\
STPM & $93.2 \%$ & $6.8 \%$ & $100.0 \%$ \\
Diploma & $97.5 \%$ & $2.5 \%$ & $100.0 \%$ \\
Degree & $97.9 \%$ & $2.1 \%$ & $100.0 \%$ \\
Not applicable & $97.9 \%$ & $2.1 \%$ & $100.0 \%$ \\
No certificate & $96.2 \%$ & $3.8 \%$ & $100.0 \%$ \\
Missing & $100.0 \%$ & $0.0 \%$ & $100.0 \%$ \\
& & & \\
Total & $95.5 \%$ & $4.5 \%$ & $100.0 \%$ \\
\hline
\end{tabular}

Instead of affecting wages, which might be prevented from falling by union activities, it could be that the labor market adjusts to the increase of skilled workers through an increase in unemployment. Looking at unemployment, we see that unemployment of individuals with post-secondary education has only increased slightly (Tables $1 \& 2$ ). Degree holders have seen their rate of unemployment increase from 2.1 percent to 3.6 percent. The unemployment rate of diploma holders has risen from 2.5 percent to 3.5 percent. The certificates category, which did not exist in 1990 and corresponds to low-level diplomas representing one year of post-secondary education, is the most severly affected category by unemployment with a 5 percent unemployment rate in 2011. The variations are thus minor, relative to the increases in quantities. Between 1990 and 2011, the labor force increased by 81 percent. At the same time, the number

\footnotetext{
${ }^{5}$ Following these authors, we decompose the change in the aggregate skill proportion into two components: $\Delta S=\sum_{i} S_{i} \bar{E}_{i}+\sum_{i} \bar{S}_{i} \Delta E_{i}$, where $S_{i}$ is the share of skilled labor at the industry level, and $E_{i}$ the employment share of each industry in total employment.
} 
Table 2: Labor Force in 2011, by highest certificate obtained

\begin{tabular}{rrrr}
\hline Degree & Employed & Unemployed & Total Labor Force \\
\hline & & & \\
USPR or similar & $97.5 \%$ & $2.5 \%$ & $100.0 \%$ \\
PMR/SPR or similar & $97.3 \%$ & $2.7 \%$ & $100.0 \%$ \\
SPM or similar & $96.7 \%$ & $3.3 \%$ & $100.0 \%$ \\
STPM or similar & $96.2 \%$ & $3.8 \%$ & $100.0 \%$ \\
Certificate & $94.9 \%$ & $5.1 \%$ & $100.0 \%$ \\
Diploma & $96.5 \%$ & $3.5 \%$ & $100.0 \%$ \\
Tertiary degree & $96.4 \%$ & $3.6 \%$ & $100.0 \%$ \\
No degree & $98.4 \%$ & $1.6 \%$ & $100.0 \%$ \\
Not applicable & $95.8 \%$ & $4.2 \%$ & $100.0 \%$ \\
& & & \\
Total & $96.9 \%$ & $3.1 \%$ & $100.0 \%$ \\
\hline
\end{tabular}

of diploma holders increased by 400 percent and that of degree holders by 654 percent. The possibility of unemployment increases as a mechanism to preserve wage premia facing constant demand thus seems highly unlikely.

\section{The Model}

The analysis is based on a dynamic general equilibrium model with a detailed description of the labor market, taking into account jobs across sectors and workers with different ages (youth and non-youth) and levels of education (Marouani and Robalino 2012). The model also formalizes educational choices and immigration flows. The following section will lay out the main equations of the model. The economy is disaggregated into 23 sectors, with 21 different factors of production, corresponding to labor of 20 different skill types, and physical capital. At the sectoral level, value added is a nested constant elasticity of substitution (CES) function of Capital and Labor. The Labor aggregate is disaggregated into three bundles: a High skilled labor bundle, a Medium skilled labor bundle and a Low skilled labor bundle. The nested production structure allows for differentiated elasticities of substitution between various factors of production.

\subsection{The production structure}

Value added is a constant elasticity of substitution function of capital and a labor aggregate $\mathrm{L}^{6}$ :

$$
X_{t}=\left(\alpha_{K} K_{t}^{1-\frac{1}{\sigma_{1}}}+\alpha_{L} L_{t}^{1-\frac{1}{\sigma_{1}}}\right)^{\frac{1}{1-\frac{1}{\sigma_{1}}}}
$$

The first order conditions imply the following factor demands:

$$
\begin{aligned}
& K_{t}=X_{t}\left(\frac{\alpha_{K} P V A_{t}}{R_{t}}\right)^{\sigma_{1}} \\
& L_{t}=X_{t}\left(\frac{\alpha_{L} P V A_{t}}{P L_{t}}\right)^{\sigma_{1}}
\end{aligned}
$$

At the following nest, $\mathrm{L}$ is decomposed into three bundles containing workers with academic degrees, vocationally trained, and secondary school graduates or lower:

\footnotetext{
${ }^{6}$ Sectoral indices have been omitted in this section for readability.
} 
Table 3: Evolution of industry labor shares and proportion of skilled labor by industry, 20072010

\begin{tabular}{rrr}
\hline Industry & $\Delta$ (laborshare) & $\Delta$ (skillsproportion) \\
\hline Agriculture & & \\
Oil \& Gas & $-4 \%$ & $203 \%$ \\
Manufacturing textile & $67 \%$ & $54 \%$ \\
Manufacturing wood & $38 \%$ & $127 \%$ \\
Manufacturing food, beverages, tobacco & $-26 \%$ & $92 \%$ \\
Manufacturing paper \& furniture & $-22 \%$ & $33 \%$ \\
Manufacturing chemicals rubber & $-3 \%$ & $13 \%$ \\
Metals, machinery, equipment NEC & $6 \%$ & $-3 \%$ \\
Electronics \& electrical & $-6 \%$ & $18 \%$ \\
Manufacturing \& transport equipment & $-11 \%$ & $11 \%$ \\
Utilities & $45 \%$ & $48 \%$ \\
Construction & $8 \%$ & $34 \%$ \\
Wholesale \& retail & $18 \%$ & $16 \%$ \\
Losistics & $15 \%$ & $20 \%$ \\
Post and telecoms & $14 \%$ & $4 \%$ \\
Finance & $22 \%$ & $13 \%$ \\
Real estate & $11 \%$ & $11 \%$ \\
Business services & $58 \%$ & $-2 \%$ \\
Education & $-3 \%$ & $34 \%$ \\
Health & $35 \%$ & $7 \%$ \\
Other services & $32 \%$ & $8 \%$ \\
Public administration & $-2 \%$ & $9 \%$ \\
& $20 \%$ & $63 \%$ \\
\hline & & $32 \%$ \\
\hline
\end{tabular}

$$
L_{t}=A_{t}\left(\alpha_{H S} H S_{t}^{1-\frac{1}{\sigma_{2}}}+\alpha_{M S} M S_{t}^{1-\frac{1}{\sigma_{2}}}+\alpha_{L S} L S_{t}^{1-\frac{1}{\sigma_{2}}}\right)^{\frac{1}{1-\frac{1}{\sigma_{2}}}}
$$

Each labor bundle is a CES aggregate of workers of different skill types. The HS bundle contains degree holders of 8 different types, corresponding to eight broad fields of study. The MS bundle contains vocationally trained, in the same 8 broad fields of study. Finally, the LS bundle contains workers of 4 educational categories: primary and less, lower secondary, upper secondary, and pre-university.

$$
\begin{gathered}
H S_{t}=A_{H S, t}\left[\sum_{f} \beta_{f} L D_{H S, f, t}^{1-\frac{1}{\sigma_{3}}}\right]^{\frac{1}{1-\frac{1}{\sigma_{3}}}} \\
M S_{t}=A_{M S, t}\left[\sum_{g} \beta_{g} L D_{M S, g, t}^{1-\frac{1}{\sigma_{4}}}\right]^{\frac{1}{1-\frac{1}{\sigma_{4}}}} \\
L S_{t}=A_{L S, t}\left[\sum_{l} \beta_{l} L D_{L S, l, t}^{1-\frac{1}{\sigma_{5}}}\right]^{\frac{1}{1-\frac{1}{\sigma_{5}}}}
\end{gathered}
$$

Each of the 20 skill types is composed of local and migrant labor: 


$$
L D_{l f, t}=\left(\alpha_{l o c} L D L_{l f, t}^{1-\frac{1}{\sigma_{6}}}+\alpha_{m i g} M I G_{l f, t}^{1-\frac{1}{\sigma_{6}}}\right)^{\frac{1}{1-\frac{1}{\sigma_{6}}}}
$$

And local labor of skill type $\mathrm{s}$ is made up of young and old workers:

$$
L D L_{l f, t}=\left(\alpha_{y} L D L A_{y, l f, t}^{1-\frac{1}{\sigma_{7}}}+\alpha_{n y} L D L A_{n y, l f, t}^{1-\frac{1}{\sigma_{7}}}\right)^{\frac{1}{1-\frac{1}{\sigma_{7}}}}
$$

\subsection{Labor Supply}

Each year, workers leave the labor force through death and retirement ${ }^{7}$. New workers enter from the educational system, upon finishing an educational cycle and deciding not to pursue further education. A skill-specific percentage of graduates (estimated from LFS data) do not enter the labor force.

\subsubsection{Educational dynamics}

Facing the above demands for workers of various skill types, origin and age, the evolution of supply of workers is determined in an educational module calibrated from data from past years. Students move between educational cycles depending on dropout rates, and the willingness to join the labor market at the end of each cycle. For low skill content-cycles, these rates are calculated as averages from the period 2009-2010. The dropout rates are calculated using the following formula:

$$
\text { dropout }_{c}=\frac{\text { enrolled }_{c, 2009}+\text { entrants }_{c, 2010}-\text { grad }_{c, 2009}-\text { enrolled }_{c, 2010}}{\text { enrolled }_{c, 2009}}
$$

For each cycle, the dropout rate is calculated as a residual. It corresponds to disappearances from the stock of enrolled between 2009 and 2010, which are not accounted for, relative to the stock of enrolled in 2009. We make the assumption that repetition rates (for which we have no information) are negligible. Graduates deciding not to pursue further education are captured by the parameter exdip:

$$
\operatorname{exdip}_{c}=\frac{\operatorname{grad}_{c, 2009}-\sum_{c}\left(\text { entrants }_{c 2,2010} \times \operatorname{transmap}_{c, c 2}\right) \times \frac{\operatorname{grad}_{c, 2009}}{\sum_{c}\left(\text { equiv }_{c, c 2} \times \operatorname{grad}_{c 2,2009}\right)}}{\operatorname{grad}_{c, 2009}}
$$

Where transmap is a mapping parameter between different educational cycles and equiv a parameter mapping cycles that are equivalent, in the sense that they can both precede $c 2$. Thus, graduates who choose not to pursue into the next cycles is the residual of the graduates from cycle $c$, less entrants into the next cycle weighted by the importance of cycle $c$ as a cycle of origin. As such, exdip refers to the percentage of graduates who leave a given cycle in 2009 less those who choose to continue into any of the next possible cycles.

$$
N E W E N R_{c, t}=\text { popent }_{c, t}+\sum_{c} G R A D_{c 2, t-1} * \operatorname{transmap}_{c, c 2} *\left(1-\operatorname{exdip}_{c, t-1}\right)
$$

Newly enrolled are equal to children arriving at school age (popent) for the primary cycle, plus last year graduates from preceding cycles, less those who choose not to pursue further studies. As such, the number of enrolled is simply equal to the number of enrolled of the previous year, less graduates and dropouts, plus newly enrolled in the current year.

$$
E N R_{c, t}=E N R_{c, t-1} \times\left(1-\text { dropout }_{c}\right)-G R A D_{c, t-1}+N E W E N R_{c, t}
$$

\footnotetext{
${ }^{7}$ The mortality and retirement rates are obtained from UNESCO data.
} 
Furthermore, we assume a stable share of graduates:

$$
G R A D_{c, t}=\text { gradrate }_{c} \times E N R_{c, t}
$$

Students hence move through the educational system cycle by cycle, depending on drop out rates and the willingness to pursue further education; a willingness that is determined by preferences and the expected rate of return to education. At the end of Form 5, students who choose to pursue higher education make a choice of entering pre-university education or seeking vocational training.

\subsubsection{Educational choices}

The hypothesis that expected wages orient the demand for a certain level of education has been confirmed in numerous studies (eg. McIntosh (2001) and Canton and Jong (2005)). Average wages by skill type and field of study have been found to be positively correlated with relative demand for education of a particular skill type and in a particular field of study (Montmarquette, Cannings, and Mahseredjian 2002; Freeman and Hirsch 2008; Beffy, Fougere, and Maurel 2012). In Belgium, Duchesne and Nonneman (1998) find some support for relative wages driving enrollment choices both in university and non-university higher education. The choice between pre-university education and vocational training is thus modeled through a constant elasticity of transformation function (CET) where the first order conditions render the following demands for vocational training and academic degrees respectively ${ }^{8}$ :

$$
\begin{aligned}
& N E W E N R_{v o c, t}=\alpha_{v o c} \times T O T N E W E N R_{t} \times\left[\frac{\frac{\sum_{g}\left(L D_{g, t} \times\left(1-U r_{g, t}\right) \times a v f w_{g, t}\right)}{\sum_{g}\left(L D_{g, t}\right)}}{\frac{\sum_{f}\left(L D_{f, t} \times\left(1-U r_{f, t}\right) \times a v f w_{f, t}\right)}{\sum_{f}\left(L D_{f, t}\right)}}\right]^{\sigma_{10}} \\
& N E W E N R_{\text {deg,t }}=\alpha_{\text {deg }} \times T O T N E W E N R_{t} \times\left[\frac{\frac{\sum_{f}\left(L D_{f, t} \times\left(1-U r_{f, t}\right) \times a v f w_{f, t}\right)}{\sum_{f}\left(L D_{f, t}\right)}}{\frac{\sum_{g}\left(L D_{g, t} \times\left(1-U r_{g, t}\right) \times a v f w_{g, t}\right)}{\sum_{g}\left(L D_{g, t}\right)}}\right]^{\sigma_{10}}
\end{aligned}
$$

The demand for vocational training thus increases according to the expected relative mean wage of vocationally trained and degree holders respectively; and with an elasticity of $\sigma_{10}$. The total number of students having decided to pursue education after finishing secondary school is thus broken down into two categories: students who continue to vocational training, and students who go on to university. For medium and high skilled, newly enrolled choose different fields of study based on preferences and expected wages in each fields. This choice is again modeled through a constant elasticity of transformation function (CET) which gives an optimal allocation of demand for skills given expected wages. We here assume that workers are have myopic expectations and believe the wage distribution by skill to remain constant and equal to that of the previous year. The first order conditions imply the following demand for educational services of type $f$, for vocational and university students respectively:

$$
\begin{aligned}
& N E W E N R F I E L D_{g, t}=\gamma_{g} \times N E W E N R_{v o c, t} \times\left[\frac{a v f w_{g, t-1}\left(1-U r_{g, t-1}\right)}{a v f w t o t_{v o c, t-1}}\right]^{\sigma_{11}} \\
& N E W E N R F I E L D_{f, t}=\gamma_{f} \times N E W E N R_{\text {deg,t }} \times\left[\frac{a v f w_{f, t-1}\left(1-U r_{f, t-1}\right)}{a v f w t o t_{d e g, t-1}}\right]^{\sigma_{12}}
\end{aligned}
$$

Where avfwtot edu,t-1 $_{\text {is }}$ ine average expected wage of diploma- and degree holding nonyouth on the labor market, with $v o c, d e g \subset e d u$. Each year, $N E W E N R_{e d u, t}$ is fixed and equal

\footnotetext{
${ }^{8}$ See the Annex for the initial CET functions
} 
to the demand for vocational and university studies respectively. These blocks of equations thereby give us educational demand by skill. These demands are confronted with supply in a sequential fashion: first, fields of study are ranked according to the wage premium associated with each one. Then, desired entrants into that field are confronted with the number of available places in the field. Students not accepted are regrouped with those desiring to enter the second rank field. A second cutoff is operated, with leftovers going into the third ranked field of study. The mechanism is repeated throughout the list of fields of study, for vocationally trained and degree holders respectively. Any students cut off from the eighth field of study are considered to be secondary school graduates of which a fraction will enter the labor force.

\subsubsection{Labor Force evolution}

Graduates from lower cycles are added to the youth labor force in the following fashion:

$$
\begin{gathered}
L S T A_{l f, y, t}=L S T A_{l f, y, t-1} \times\left(1-\text { transage }_{l f}\right)+\sum_{c}\left(\operatorname{GRAD}_{c, t-1} \times \operatorname{exdip}_{c} \times \operatorname{edumap}_{c, l f} \times\left(1-\text { inact }_{l f}\right)\right) \\
+\sum_{c 2}\left(\operatorname{ENR}_{c, t} \times \text { dropout }_{c} \times\left(1-\text { inact }_{l f}\right)\right) \times \sum_{c}\left(\text { transmap }_{c, c 2} \times \text { edumap }_{c, l f}\right)
\end{gathered}
$$

That is, the local labor force of skill $l f$ equals the previous year's local labor force of skill $l f$, less those workers who flow from the young to the not young category. Graduates from cycle $c$ who choose not to continue their studies are mapped to a labor skill, and a percentage of them are added to the labor force according to their labor force participation rate. Finally, dropouts from cycles above $c$ are added to the relevant labor force category using mapping parameter transmap, denoting passages between cycles. For vocational and university students, the logic is the following:

$$
L S T A_{l f, y, t}=L S T A_{l f, y, t-1} \times\left(1-\text { transage }_{l f}\right)+\operatorname{Min}_{\left(C A N D I D_{l f, t-n}, \text { places }_{l f, t-n}\right) \times \text { inact }_{l f}}
$$

The labor force holding diplomas and degrees is thus equal to diploma and degree graduates in the labor force the previous year, less those who transit to the not young category. Students who were accepted into their desired field of study are added, a percentage being removed depending on the labor participation rate of the category in question. The index $n$ reflects the time it takes to complete a given cycle. We have set $n$ to equal 4 years for all degree students, and 2 years for all vocational degrees, reflecting the average duration of these cycles in Malaysia. The inclusion of a delay between entrance in a given field and labor market participation has important implications. During the time of studies, workers are effectively immobilized, such that any increase in the number of students is likely to carry an initial negative impact on growth. In short, instead of being potential low skilled workers these individuals do not contribute to production. We thus include the temporal dimension of the efficiency of education policy in the model.

Finally, the evolution of older workers depends on the transit rate between age groups, and the mortality and retirement rates of old workers:

$$
L S T A_{l f, n y, t}=L S T A_{l f, n y, t-1} \times\left(1-\operatorname{mort}_{l f, t}-\operatorname{retir}_{l f, t}\right)+\operatorname{transage}_{l f} \times L S T A_{l f, y, t-1}
$$

\subsection{The Migrant block}

Immigration in Malaysia has increased substantially over the last decades, potentially influencing labor market dynamics. These migrants tend to be low educated, arriving in Malaysia from 
primarily Indonesia and the Philippines. Various push and pull factors explain the supply of migrants in Malaysia. We model the total supply of migrants using a CET function, where the evolution of the migrant stock of a given skill level depends on the relative wage premium of of migration in a given year compared to the relative wage premium in the base year.

$$
S M I G_{l f, t}=\sum_{A C} I M M I G_{A C, l f, 2005} \times\left(\frac{\frac{a v f w m_{l f, t}}{w d o m_{l f, t}}}{\frac{a v f w m_{l f, 2005}}{w d o m_{l f, 2005}}}\right)^{\sigma_{8}}
$$

Furthermore, migrants move between sectors according to relative wages and initial preferences:

$$
S M I G_{l f, t}=\sum_{A C}\left[\gamma_{A C, l f} \times I M M I G_{A C, l f, t}^{1+\frac{1}{\sigma_{9}}}\right]^{\frac{1}{1+\frac{1}{\sigma_{9}}}}
$$

Migrants thus make their decision sequentially. First, the decision to migrate is taken based on expected wages and the elasticity of substitution. Once immigrated, they will reallocate between sectors depending on the wage rate and the elasticity of the migrant sectoral supply.

\subsection{Labor Market Adjustments}

Migrants and local workers' wages are assumed to be different due to an imperfect substitution by employers (Özden and Wagner 2013). It is assumed that the local wage does not clear the labor market, such that there is unemployment among locals. The wage is modeled using a wage curve, reflecting the often observed empirical relationship between wage and unemployment. The local average wage by skill is thus given by:

$$
\operatorname{logaf} w_{l f, t}=\beta_{1 l f}+\beta_{2 l f} \times \log U r_{l f, t}
$$

Sectoral wages are then equal to the average wage, plus an exogenous wage differential:

$$
w f_{A C, l f, t}=a f w_{l f, t} \times \text { fwdist }_{A C, l f}
$$

Initially, the migrant wage clears the migrant labor market. We thus make the assumption that there is no migrant unemployment. Furthermore, reasonably in line with the regulatory framework, we assume that migrants do not pay social security. Following the minimum wage law passed in Malaysia in 2012, restrictions are imposed on the market wage from 2013. It follows that wages no longer clear the migrant labor market. Since there is no migrant unemployment, the introduction of a minimum wage -supposing it is binding -implies rationing of migrants in Malaysia. The level of the minimum wage is set according to the actual minimum wage introduced, deflated to reflect 2005 prices (since the model is exempt from inflation). The minimum wage is introduced sequentially. First, market wages below the minimum wage level are fixed at the minimum wage rate. The model is then resolved to allow for sectoral adjustments to take place. Any market wage having fallen below the minimum wage rate is fixed at the minimum wage, and the procedure is repeated. The sequence stops when all wages are equal to or above the minimum wage rate.

\subsection{Closure and dynamics}

The model has five closures: a macro closure, a government closure, an external balance closure, a labor market closure and a closure of the social security accounts. Concerning the macro closure, it is savings driven (households' marginal propensity to save is exogenous), which means that the level of investment is determined by the level of total available savings in the economy (including foreign savings). Hence as savings increase, the stock of capital and output increase. 
The government closure chosen consists in fixing government expenditures as a constant share of GDP and tax rates and leaving the government budget balance endogenous. The social security account is modeled separate from the Government budget. It earns its income from employers' pay-roll taxes and pays benefits that are distributed to households. The social security balance is endogenous. The foreign balance closure consists of fixing the exchange rate and leaving the current account balance endogenous. The formal labor market closure consists of a joint determination of unemployment and average local wages through the wage curve described above and no unemployment for foreign workers (wages clear the market).

Model dynamics are of the sequential type. Capital accumulation is sectoral. Each year the stock of capital in each sector corresponds to last year's stock plus new investment, minus the depreciation of capital. Sectoral investment has been modeled as a function of the sectoral stocks of capital, sectoral rates of return to capital and capital acquisition costs. As already mentioned, the evolution of the active population by skill is modeled within the education block, which relies on the actual performance rates of the education system and endogenous educational choices in Malaysia. Government and foreign debts increase (decrease) with the yearly level of the net deficit (surplus) of Government and foreign savings.

\section{Data and calibration}

\subsection{The Database}

We build a social accounting matrix using an input-output table of 2005, the base year for the simulations. A Social security contributions account has been added, with a fixed percentage of employer and worker contributions being drawn from labor income. Total employment is taken from the 2007 LFS, the first survey for which wages are available. It represents wage earners in each sector, with the exception of the agricultural sector where employment refers to all employed due to the particular nature of this sector (hosting many informally employed workers) ${ }^{9}$ and health (where employment corresponds to the estimated amount of wage earners for 2005).

Total value-added (including social security benefits) in each sector is taken from the 2005 IO table. Wage related data come from the LFS. In the agriculture, health and education sectors, aggregate wage bills are those of the 2005 I-O tables. In the remaining sectors, wage bills are taken from the LFS 2007 by multiplying mean wages by skill and industry with the number of workers of that skill and industry (the difference between these and the original wage bill is imputed from capital remuneration). Thus, mean wages and wage earners are kept in accordance with the LFS in all except the three sectors mentioned. For those three sectors the standard methodology could not be used since the imputed wage bill would necessitate a negative capital remuneration. The original wage bill is thus kept, and wages are imputed and not equal to those of the LFS.

Investment by origin is taken from the 2005 Input-Output (IO) table and is portioned out to destination sectors. Information from a report titled "National Accounts Capital Stock Statistics" by the DOS proved very useful for this exercise. Since the data reflect a higher aggregation than the one used for the estimation we assume that investment is equally distributed among our sub-sectors. Ideally, an investment origin-destination matrix would have been used, but such a matrix was not available. Current results will thus fail to accurately capture some sub-

\footnotetext{
${ }^{9}$ The LFS survey does not include workers in communal housing, which is common among migrant agricultural workers, who are thus likely to be underrepresented in the LFS.
} 
sector dynamics that are due to relatively high or low investment with respect to sector size. World and local growth rates are taken from the World Bank Databank. Data on enrollment, intake and graduates for each cycle were available for 2009 and 2010. This data is used to calculate (for each cycle) the drop out-rates and the share of graduates who move to the next cycle. Enrollment data for the base year are estimated from a dynamic calibration exercise, retracing the evolution of educational outcomes between 2005 and 2010.

Using production and LFS data from 2005 through 2011, we dynamically calibrate the main parameters of the model through an iterative process. The result from this exercise is that the reference scenario is reasonably in line with the Labor Force Survey figures and the evolution of the main variables at the macro and sectoral levels.

\subsection{Calibration}

Model parameters include initial values of endogenous variables, as well as exogenous parameters. The Social Accounting Matrix provides such values for production and consumption, exports, imports etc. Labor Force Surveys provide us with information on wages and employment status of migrants and locals. Some inobservable parameters can be calculated using initial values obtained from these sources. Others, such as elasticities of substitution, have to be estimated. When possible, we have attempted to estimate these elasticities. When impossible, reasonable values from the literature have been used.

As for the demand elasticity of substitution between high-skilled labor and capital, we follow Card and Lemieux (2001) and derive elasticities of substitution between workers of different age groups, education levels, fields of study as well as elasticities of different labor aggregates of these worker categories. The limited number of years for which we have data on wages sharply limits the regression results, and significant coefficients were not obtained for the full production structure. There are however indications of elasticities decreasing as we move up the production structure. The price-elasticities of demand for migrants with respect to locals have been estimated from LFS data ${ }^{10}$.

We consider current macroeconomic trends to prevail. As such, the savings rate and the rate of increase of foreign direct investment have been set to values producing reasonable figures, in line with IMF data for the period 2005-2011. Furthermore, we are assuming the government deficit to continue its downward trend, declining to $3 \%$ of GDP in 2015, and completely absorbed in $2020^{11}$.

\section{A micro accounting module}

A simple microsimulation module is added to the CGE framework in order to study distributional impacts of SBTC and educational rationing. Due to lack of data on self-employment revenues and consumption, a full structural model of household behavior is not attempted. Since we are focusing on wage inequalities, a simple arithmetic micro accounting approach is used, linking model outcomes to micro level data. The LFS survey contains information on wage earners only, which is why we exclude interest rate variations from our analysis.

We use the most recent exhaustive LFS data set, that of 2010, to implement factor price variations. Since our simulations produce effects that are likely to be important only in the

\footnotetext{
${ }^{10}$ We thank Caglar Ozden and Mathis Wagner for providing us with these elasticities.

${ }^{11}$ As by PEMANDU objectives.
} 
medium- long-term framework (especially considering educational rationing), we seek to examine the alternative effects by 2020 from our reference scenario and our simulated scenarios. In a sense, we are comparing two counterfactuals. The variation in real wage income between 2010 and 2020 for an individual in industry $A C$, of skill $f$ and age group $a$ is thus:

$$
\Delta W_{2020 / 2010, A C, f, a}=W_{A C, f, a, 2010} \times C_{S c e n, A C, f, a}
$$

where $\mathrm{C}$ is a vector of factor payment variations issued from the various macro model scenarios. Thus, the individual wage impact of a simulation simply amounts to:

$$
\Delta W_{A C, f, a}=W_{A C, f, a, 2010} \times\left(C_{S i m, A C, f, a}-C_{R e f, A C, f, a}\right)
$$

Since our interest in doing this simple exercise is to examine how skill-biased technological change and educational policy affects distribution of wage incomes, we look at Gini coefficients and decile ratios, included along with macro results in the following section.

\section{Simulations and results}

The following section presents the simulations run and their results. Our first simulation assumes the skill-bias of technological change to be zero, i.e. that the overall rate of technological progress, calibrated from the dynamic calibration exercise using exogenous productivity growth rates, is affecting skilled land unskilled labor alike. Secondly, we simulate a rationing in the number of places at institutes of higher learning. For simplicity's sake, we compare an open-door policy, considered to be our benchmark scenario, with a scenario where the number of places available is equal to that of 2005 , our base year.

\subsection{Malaysia without skill-biased technological change}

What would have been the absorption of graduates by the labor market if technological progress in Malaysia were not biased toward skilled labor? How would the wage premia have reacted? We run a two-fold reference scenario, one with and one without skill-biased technological progress, both calibrating overall productivity growth given exogenous sectoral productivity growths and GDP growth rates (using historical figures, then assumed to be 5\%). The reference scenario has been calibrated in order to reproduce as closely as possible the evolution of wages, unemployment and other endogenous variables between 2005 and 2011. We have settled on a skill bias of $4 \%$ annually for two reasons. Firstly, an estimation of the residual $A=\Delta \frac{\theta_{S}}{\theta_{U}}$ from only four data points (the ones for which we have wages) gives us an upper limit of skill-biased technological change of $9 \%$. Choosing roughly half this figures makes us reasonably sure we are not overestimating the effect of SBTC. Furthermore, this figure gives us a reference scenario reasonably in line with the evolution of some main macro and sectoral variables.

Our first simulation assumes neutral technological change. Since the global productivity coefficient is calibrated to sectoral productivity growth rates and a GDP target figure, this means that removing the skill bias does not imply modifying aggregate productivity growth. Furthermore, the skill-biased technological change was applied to all tertiary educated, i.e. certificate, diploma and degree holders. As can be seen from Figure 3, in the absence of skill-biased technological change, less skilled workers would have had a higher wage growth than in the reference scenario. On the other hand, tertiary educated -vocationally and academic alike -would have seen their wages decrease, thus eroding returns to education. Detailed breakdowns by field of study for Diploma holders and degree holders, and by level of education for less skilled can be found in the Annex. They show that for Diploma holders, the biggest winners from SBTC are engineers. For degree holders, those with degrees in Agriculture have benefited the most. 
Figure 3: Evolution of wages of Malaysian wage earners without SBTC

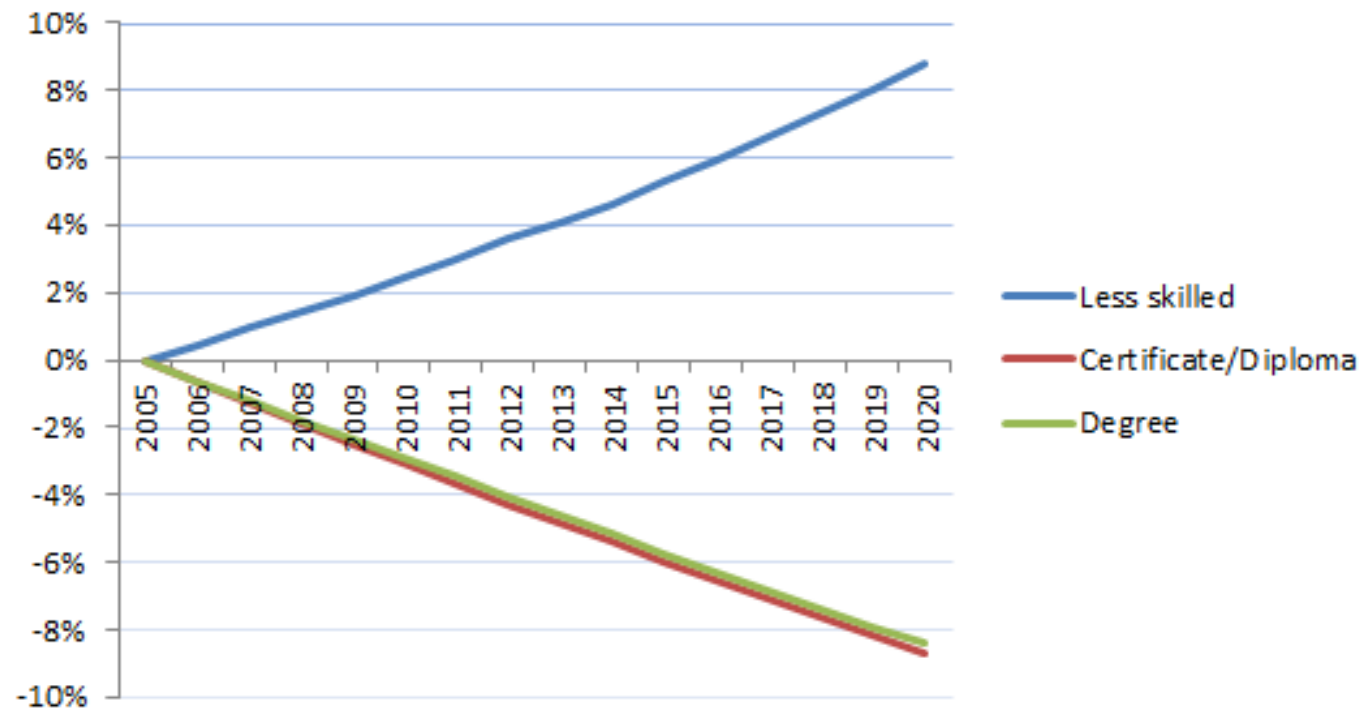

Figure 3 shows that the Agricultural sector is the sector who has known the highest upskilling in the period 2007-2010. This large sector has the highest ratio (more than 95\%) of unskilled to skilled labor, implying that an important substitution of skilled for unskilled labor needs to take place, significantly affecting wages of the high skilled.

Looking at unemployment (Figure 4), we see that the tendency is the same as for wages. Had skill-biased technological change not been present, the unemployment rates of tertiary educated would have been around 15-20\% higher, while those of less skilled workers would have been $15 \%$ lower. Thus, SBTC has clearly had a positive impact on the labor market outcomes of graduates in Malaysia.

Figure 4: Evolution of unemployment of Malaysian wage earners without SBTC

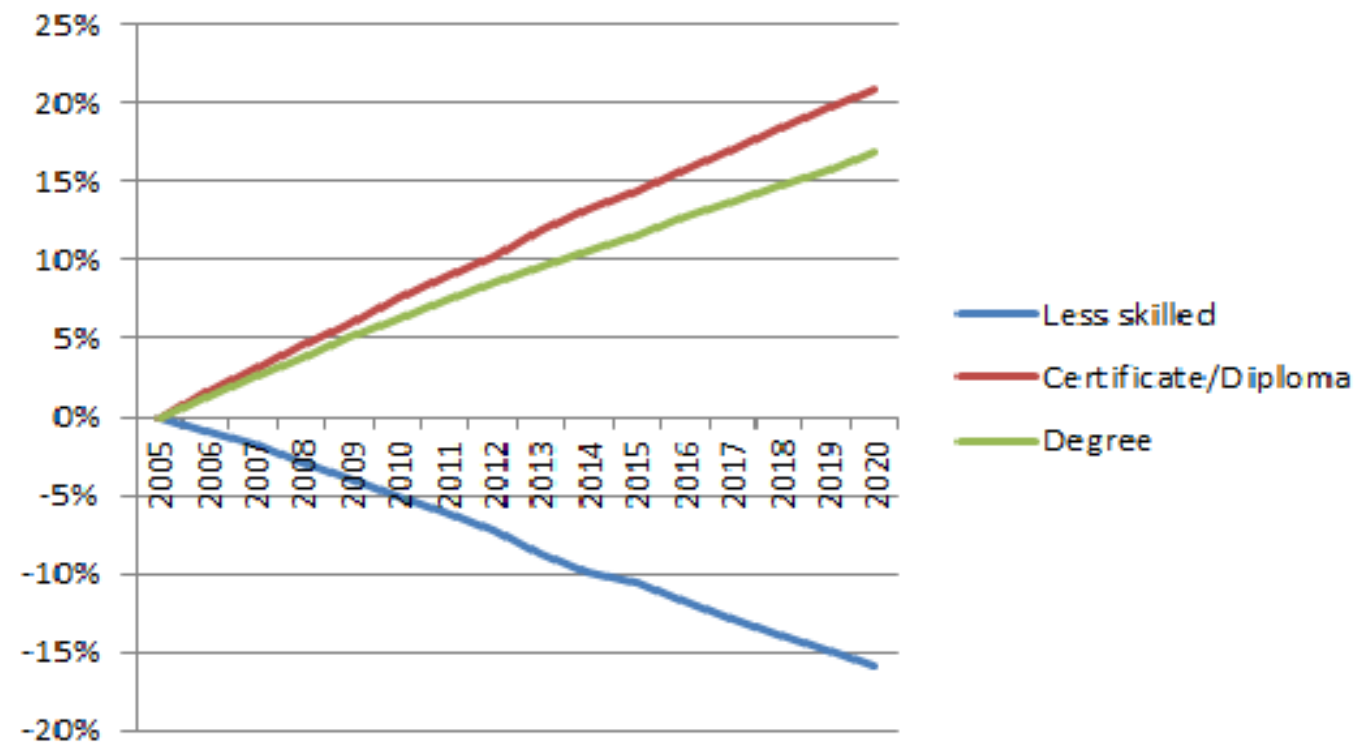

The macroeconomic impacts over the period are minor (mainly since the model is calibrated to the same GDP target figures). Unemployment would however have been slightly lower during 
the period but returning to a very close figure (3.1\%) by 2020. Results also show that immigration would have been higher had SBTC not prevailed. Malaysia's immigration in recent years has been important, important enough to spark a concern among the government about its economic and social impact. Our results however show that the numbers could have been higher. Had productivity increases been unbiased, the migrant stock would have been $14 \%$ higher by 2020. Unbiased technological progress, relatively more favorable to low-skill intensive sectors, can thus be seen as increasing the pull factor in the Malaysian context, where the main migration pool is made up of low-skilled Indonesians and Filipinos.

Table 4: Sectoral production growth differentials 2010-2020 without SBTC (private sectors)

\begin{tabular}{rr}
\hline Agriculture & $11 \%$ \\
Oil \& Gas & $3 \%$ \\
Manufacturing food, beverages, tobacco & $10 \%$ \\
Manufacturing textile & $2 \%$ \\
Manufacturing wood & $12 \%$ \\
Manufacturing paper \& furniture & $3 \%$ \\
Manufacturing chemicals rubber & $-1 \%$ \\
Metals, machinery, equipement NEC & $0 \%$ \\
Electronics \& electrical & $-2 \%$ \\
Manufacturing \& transport equipment & $-1 \%$ \\
Utilities & $1 \%$ \\
Construction & $1 \%$ \\
Wholesale \& retail & $8 \%$ \\
Logistics & $4 \%$ \\
Post and telecom & $0 \%$ \\
Finance & $-1 \%$ \\
Real estate & $0 \%$ \\
Business services & $-10 \%$ \\
\hline
\end{tabular}

Table 4 shows the production growth differentials from 2010 to 2020 in the absence of skillbiased technological change. It suggests that SBTC has led to structural change, benefiting sectors such as Business services, Finance and certain types of Manufacturing, the common denominator of which is a large share of skilled labor. Symmetrically, it has played a role in the relative decline of sectors such as Wood or Wholesale \& Retail. Thus, the recent evolution of Malaysia toward a more skill-intensive economy, a policy target, has been facilitated by technical progress biased toward skilled labor.

\subsection{Constraining the supply of higher education}

Our reference scenario supposes no rationing of supply of educational services in Malaysia. Demand factors alone thus determine the evolution of skilled labor. In this simulation, we restrain the supply of educational services to that of the base year, 2005. Every year, the number of places in each field of study is thus equal to the number of places available in $2005^{12}$. We here assume the cycle of diploma studies to be two years, and that of degree studies to be four years. An increased enrollment in degree studies would therefore only create an increase in high skilled labor four years later.

\footnotetext{
${ }^{12}$ An important caveat here is that we do not actually know the number of places in 2005, only the number of enrolled in each field of study. It is possible that more places were available in some fields.
} 
Figure 5: Evolution of unemployment of degree holding wage earners with a restriction in places

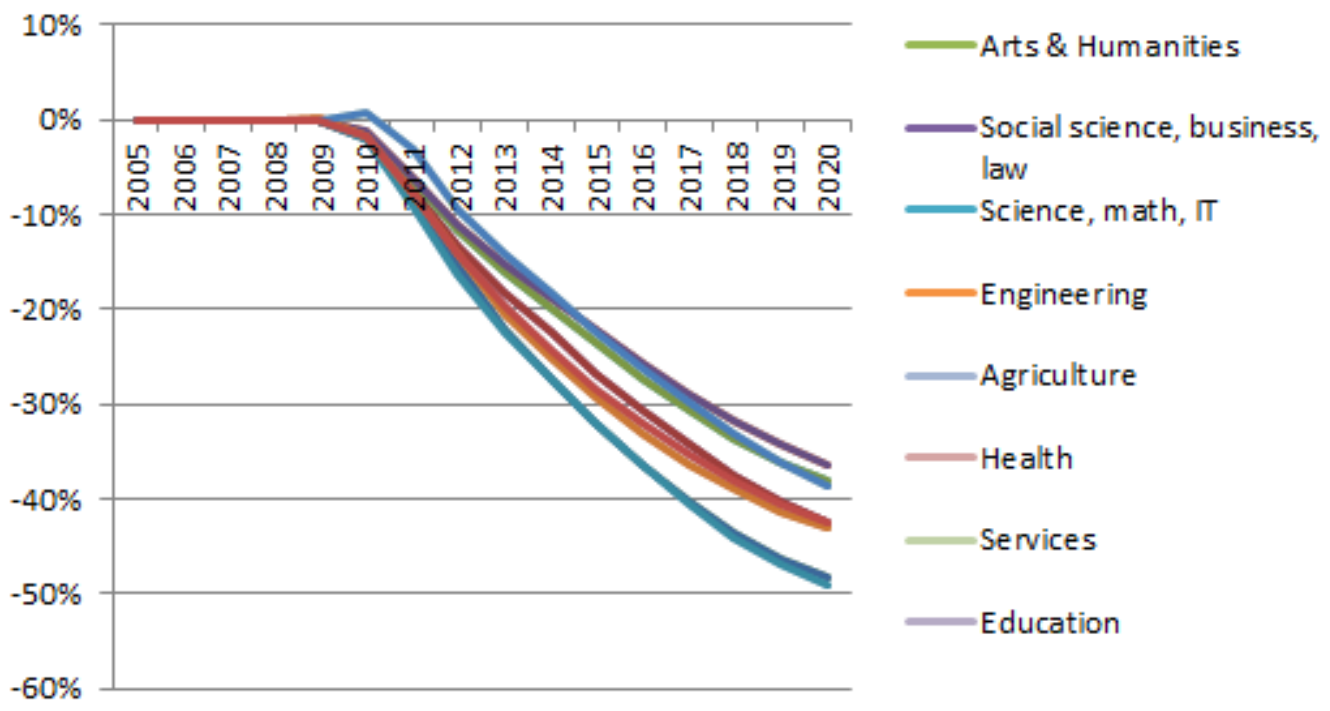

Table 5: Sectoral production growth differentials 2010-2020 with rationing (private sectors)

\begin{tabular}{rr}
\hline Agriculture & $3.6 \%$ \\
Oil \& Gas & $1.4 \%$ \\
Manufacturing food, beverages, tobacco & $3.0 \%$ \\
Manufacturing textile & $1.1 \%$ \\
Manufacturing wood & $4.5 \%$ \\
Manufacturing paper \& furniture & $1.4 \%$ \\
Manufacturing chemicals rubber & $-0.1 \%$ \\
Metals, machinery, equipment NEC & $0.1 \%$ \\
Electronics \& electrical & $0.1 \%$ \\
Manufacturing \& transport equipment & $-0.5 \%$ \\
Utilities & $0.5 \%$ \\
Construction & $0.4 \%$ \\
Wholesale \& retail & $4.8 \%$ \\
Logistics & $1.9 \%$ \\
Post and telecom & $0.2 \%$ \\
Finance & $-0.4 \%$ \\
Real estate & $0.1 \%$ \\
Business services & $-5.1 \%$ \\
\hline
\end{tabular}

Figure 5 shows the evolution of unemployment of various high-skilled categories when places are kept constant. Unsurprisingly, by 2009, as the effects translate into a lower amount of degree holders than in the reference scenario the unemployment of degree holders starts to decrease. At the end of the period, unemployment rates are $35 \%$ to $50 \%$ lower than in the reference scenario. The effect is also felt on wages, which would have been up to $20 \%$ higher by the end of the period (See Annex). By constraining access to higher education, a rent is created and awarded to those in possession of a tertiary education. For diploma holders, there is more variation in unemployment decreases and wage increases (See Annex). Some fields of study experience large increases while others get relatively minor ones. In particular, diploma holders in health do not benefit much from the rationing. This is partially due to the fact that the demand for health 
diplomas was falling in the reference scenario. Rationing actually creates a slight increase in the long term supply of health diploma graduates, since some of those diploma students that are cut out from more desirable fields due to rationing end up joining health programs as a fall back option.

Looking at sectoral production growth differentials over the decade 2010-2020, we find disparate results across sectors. Several mechanisms are at play. Firstly and most intuitively, rationing increases the relative cost of skilled labor. Sectors who are relatively intensive in unskilled labor will thus benefit. The most unskilled labor-intensive sectors (Agriculture, Wood, Wholesale \& Retail Trade) are therefore those where production increases the most. Symmetrically, the most skill-intensive sectors (Business services, Finance and Manufacturing of transport equipment) see their production decrease. Secondly, a variation of wage costs affects most those sectors who are relatively labor intensive. This explains why Manufacturing of wood benefits more than Agriculture from the rationing, Agriculture being more capital-intensive. Among the relatively skill-intensive sectors, the most capital-intensive sectors such as Finance are less hurt by the rationing than relatively labor-intensive ones such as Business services.

Looking at figures 15-18 in the Annex provides insight into the determinants of wage shifts and their sensitivity to variations in these determinants. Skill biased technological change is indeed a strong one, as has been shown in the previous results. However, the magnitude of the bias sharply correlates to the subsequent wage loss (gain) of more (less) skilled workers. Furthermore, the elasticity of substitution between the three main labor bundles is also a strong determinant of the distributional effects of skill-biased technological change and educational rationing. We feel that our main hypotheses are reasonable. Our main variable, the skill shifter, is at $4 \%$ although the residual estimated stood at $9 \%^{13}$ The elasticity of substitution between skilled labor bundles is also conservatively set at 1.5. As a matter of comparison, Katz and Murphy (1992) find an elasticity of supply between high school and college labor of 1.4 for the United States. They do not however implicitly account for substitutatbility within these two labor aggregates. When doing so, Card and Lemieux (2001) find estimates ranging between 2 and 2.5 in the UK and US.

\subsection{Distributional results}

The micro accounting exercise shows that the scenarii considered have substantially different impacts on Gini coefficients and interdecile ratios. In all cases, however, the massification of higher education together with SBTC bring about a decrease in overall wage inequality, as confirmed by the systematically lower Gini coefficients of our counterfactual scenarii. The same holds true for the interdecile measures, which are systematically lower than in the 2010 LFS (the exception being the p90/p50 indicator in Simulation 2).

Table 6: Summary of distributional indices from micro accounting exercise

\begin{tabular}{rrrrrr}
\hline & 2010 LFS & Ref. & Sim. 1 & Sim. 2 & Sim. 3 \\
\hline Gini coefficient & 0.40743 & 0.3782 & 0.36686 & 0.39393 & 0.38078 \\
p90/p10 & 6.415 & 5.66 & 5.458 & 6.133 & 5.695 \\
p90/p50 & 2.52 & 2.399 & 2.301 & 2.559 & 2.425 \\
\hline
\end{tabular}

As stated above, the reference scenario corresponds to skill-biased technological change and

\footnotetext{
${ }^{13}$ Albeit with only four data points.
} 
an open-door educational policy. This is what we consider to be the path Malaysia is currently on. The increased educational attainment of Malaysians will lead to a wage compression, substantially reducing wage inequality (almost a 3 point drop in the Gini coefficient). When comparing this with a stiuation without SBTC, maintaining the educational policy, the corresponding drop in the Gini is about 4.1. Skill-biased technological change thus prevented a reduction in wage inequality over the period. Similarly, both interdeciles ratios would have been lower, had SBTC not been present.

Turning to educational policy, the second simulation shows the counterfactual Gini coefficient and interdecile ratios in a situation with SBTC and with educational rationing. Thus, the Gini coefficient would have been 1.6 points higher had the number of educational places been maintained at their 2005 level. The open-door policy of the Malaysian government has thus contributed to a decrease in wage inequality. Furthermore, simulation 3 (No SBTC, rationing) shows that the impact of rationing is lower, but not far from that of SBTC. It thus seems that the open-door educational policy has counteracted the inequlity maintaining effect of skill-biased technological change in Malaysia.

The full story of educational impacts on inequality should mention social returns to education. While private returns have largely been the focus of the literature (although a sizeable literature on social returns to education exists), externalities of educational accumulation might impact the distribution of income in indirect ways. Primarily, there is an evident link between education and the innovation process, likely to impact technical progress directly. The impact of this nexus on the relative productivity bias is however uncertain and we therefore assume the absence of such an effect. Secondly, spillover effects in worker productivity might be expected. It is plausible that an individual in training will increase not only his or her productivity, but also that of his or her coworkers, for example by introducing new ideas or forms of organization of the workplace. This is perhaps the most relevant type of externality for our purposes. Acemoglu and Angrist (1999) try to estimate social returns using variations in compulsary schooling laws in U.S. states. They find little evidence of a higher social than a private return. Furthermore, to our knowledge there are no studies trying to estimate the social returns to education in Malaysia. Again, we are unable to ascertain any impact on the skill bias of technological change from these mechanisms.

\section{Conclusion}

This article has looked at the labor market impacts of two alternative scenarios; a neutral technological change, and a rationing of places available in tertiary education. Using a dynamic general equilibrium framework in which we extensively model educational choices both on the demand and the supply side, while taking into account immigration decisions, we are able to fully endogeneize labor supply dynamics in the Malaysian context.

Our results show that in the absence of skill-biased technological change, relatively skilled wage earners should have expected lower wages and higher unemployment, while unskilled labor would have been able to expect higher wages and lower unemployment. The absence of SBTC would also have meant increased migration. We also show that skill-biased technological change has led to structural change, benefiting sectors with a large share of skilled labor, such as Business services.

With rationing of the supply of higher education, we find that rents are created for high skilled workers, who would have seen their wages increase and unemployment decrease. At the sectoral level, we identify two mechanisms affecting sectoral production growth. Relatively less 
expensive unskilled labor, benefiting low skill-intensive sectors; and substitution effects among high skill-intensive sectors favoring the more capital-intensive sectors. These macro effects translate into distributional effects in the micro accounting module. We show that skill-biased technological change and rationing of educational services both have adverse effects on wage inequalites in the medium-term, although even with both mechanisms in play we would expect wage inequalities to drop. It seems therefore that the expansive educational policy adopted in Malaysia has counteracted some of the increase in inequalities expected from skill-biased technological change. The presence of skill-biased technological change in Malaysia thus constitutes a case for continued open enrolment policies to reduce wage inequalities.

In this paper we assume that total factor productivity and skill-bias are unrelated, to be able to isolate the effect of skill bias on the evolution of skill-specific unemployment and wage rates. Further research should be aimed at understanding in depth the linkages between skill-biased technological change and total factor productivity. 


\section{References}

Acemoglu, Daron (2002). "Directed Technical Change". In: Review of Economic Studies 69.4, pp. 781-809.

Acemoglu, Daron and Joshua Angrist (1999). How large are the social returns to education? Evidence from compulsory schooling laws. Tech. rep. National bureau of economic research.

Autor, David H., Lawrence F. Katz, and Melissa S. Kearney (2008). "Trends in U.S. Wage Inequality: Revising the Revisionists". In: The Review of Economics and Statistics 90.2, pp. 300-323.

Autor, David H., Lawrence F. Katz, and Alan B. Krueger (1998). "Computing Inequality: Have Computers Changed The Labor Market?" In: The Quarterly Journal of Economics 113.4, pp. 1169-1213.

Autor, David H., Frank Levy, and Richard J. Murnane (2003). "The Skill Content Of Recent Technological Change: An Empirical Exploration". In: The Quarterly Journal of Economics 118.4, pp. 1279-1333.

Beffy, Magali, Denis Fougere, and Arnaud Maurel (2012). "Choosing the field of study in postsecondary education: Do expected earnings matter?" In: Review of Economics and Statistics 94.1, pp. $334-347$.

Berman, Eli, John Bound, and Stephen Machin (1998). "Implications Of Skill-Biased Technological Change: International Evidence". In: The Quarterly Journal of Economics 113.4, pp. 1245-1279.

Berman, Eli and Stephen Machin (2000). "Skill-Based Technology Transfer around the World". In: Oxford Review of Economic Policy 16.3, pp. 12-22.

Blaug, M and B Ahamad (1974). The Practice of Manpower Forecasting.

Blaug, Mark (1967). "Approaches to educational planning". In: The economic journal, pp. 262287.

Canton, Erik and Frank de Jong (2005). "The demand for higher education in The Netherlands, 1950-1999". In: Economics of Education Review 24.6, pp. 651-663.

Card, David and Thomas Lemieux (2001). "Can Falling Supply Explain The Rising Return To College For Younger Men? A Cohort-Based Analysis". In: The Quarterly Journal of Economics 116.2 , pp. 705-746.

Caselli, Francesco and Wilbur John Coleman (2006). "The World Technology Frontier". In: American Economic Review 96.3, pp. 499-522.

Chung, T. P. (2003). "Returns to education: updates for Malaysia". In: Applied Economics Letters 10.13, pp. 837-841.

Cloutier, Marie-Hélène, John Cockburn, and Bernard Decaluwé (2008). Education and Poverty in Vietnam: a Computable General Equilibrium Analysis. Cahiers de recherche 0804. CIRPEE.

Deme, Mamit, David Franck, and Nadeem Naqvi (2005). "A General Equilibrium Skill Acquisitions Model Of Development For Lesotho". In: Journal of Economic Development 30.1, pp. $15-29$.

Duchesne, I and W Nonneman (1998). "The demand for higher education in Belgium". In: Economics of Education Review 17.2, pp. 211-218.

Freeman, James A and Barry T Hirsch (2008). "College majors and the knowledge content of jobs". In: Economics of Education Review 27.5, pp. 517-535.

Glytsos, Nicholas P (1990). "Modelling future higher education-labor market imbalances: A multi-scenario approach". In: Economics of Education Review 9.1, pp. 1-23.

Goldin, Claudia and Lawrence F. Katz (1998). "The Origins Of Technology-Skill Complementarity". In: The Quarterly Journal of Economics 113.3, pp. 693-732. 
Guan, Lee Hock (2012). "Racial Citizenship and Higher Education in Malaysia". In: The New Economic Policy in Malaysia. Ed. by Edmund Terence Gomez and Johan Saravanamuttu. Singapore: NUS Press.

Jung, Hong-Sang and Erik Thorbecke (2003). "The impact of public education expenditure on human capital, growth, and poverty in Tanzania and Zambia: a general equilibrium approach". In: Journal of Policy Modeling 25.8, pp. 701-725.

Kabbani, Nader and Ekta Kothari (2005). "Youth employment in the MENA Region: A situational assessment". In: Washington, DC: World Bank SP Discussion Paper 534.

Katz, Lawrence F and Kevin J Murphy (1992). "Changes in Relative Wages, 1963-1987: Supply and Demand Factors". In: Quarterly Journal of Economics 107.1, pp. 35-78.

Kenayathulla, Husaina Banu (2013). "Higher levels of Education for higher private returns: New Evidence from Malaysia". In: International Journal of Educational Development 33, pp. 380-393.

Machin, Stephen and John Van Reenen (1998). "Technology And Changes In Skill Structure: Evidence From Seven Oecd Countries". In: The Quarterly Journal of Economics 113.4, pp. 1215-1244.

Marouani, Mohamed A. and David A. Robalino (2012). "Assessing interactions among education, social insurance and labour market policies in Morocco". In: Applied Economics 44.24, pp. 3149-3167.

Marouani, Mohamed Ali (2010). "More jobs for university graduates: some policy options for Tunisia". In: Applied Economics Letters 17.10, pp. 933-937.

McIntosh, Steven (2001). "The Demand for Post-Compulsory Education in Four European Countries". In: Education Economics 9.1, pp. 69-90.

Montmarquette, Claude, Kathy Cannings, and Sophie Mahseredjian (2002). "How do young people choose college majors?" In: Economics of Education Review 21.6, pp. 543-556.

Özden, Çaglar and Mathis Wagner (2013). "Immigrants versus Natives? Displacement and Job Creation". In:

Pritchett, Lant (1996). Where has all the education gone? Policy Research Working Paper Series 1581. The World Bank.

Psacharopoulos, George (1991). "From manpower planning to labour market analysis". In: Int'l Lab. Rev. 130, p. 459 .

- (2006). "World Bank policy on education: A personal account". In: International Journal of Educational Development 26.3, pp. 329-338.

Sanders, Mark and Bas ter Weel (2000). Skill-Biased Technical Change Theoretical Concepts, Empirical Problems and a Survey of the Evidence. DRUID Working Papers 00-8. DRUID, Copenhagen Business School, Department of Industrial Economics and Strategy/Aalborg University, Department of Business Studies.

Savard, Luc and Epiphane Adjovi (1998). "Externalités de la santé et de l'éducation et bien-être : un modèle d'équilibre général calculable appliqué au Bénin". In: L'Actualité Economique 74.3, pp. 523-560.

Wieling, Myra and Lex Borghans (2001). "Discrepancies between Supply and Demand and Adjustment Processes in the Labour Market". In: LABOUR 15.1, pp. 33-56.

World Bank (2008). The Road Not Traveled: Education Reform in the Middle East and Africa. Tech. rep.

- (Forthcoming). Developing Skills for Innovation and High Income Economy in Malaysia. Tech. rep.

Yamada, Gustavo and Juan Castro (2009). "Educational attainment, growth and poverty reduction within the MDG framework: simulations and costing for the Peruvian case". In: Journal of Economic Policy Reform 12.1, pp. 57-73. 


\section{Annex}

Table 7: Variables used in the CGE model

\begin{tabular}{|c|c|}
\hline$X_{A C, t}$ & Composite production by sector $\mathrm{AC}$ in year $\mathrm{t}$ \\
\hline$K_{A C, t}$ & Capital stock by sector \\
\hline$L_{A C, t}$ & Aggregate labor bundle \\
\hline$P V A_{A C, t}$ & Value added price \\
\hline$R_{A C, t}$ & Interest rate \\
\hline$P L_{A C, t}$ & Price of aggregate labor bundle \\
\hline$H S_{A C, t}$ & High-skilled labor bundle \\
\hline$M S_{A C, t}$ & Medium-skilled labor bundle \\
\hline$L S_{A C, t}$ & Low-skilled labor bundle \\
\hline$L D_{A C, f, t}$ & High-skilled labor bundle of type $f$ \\
\hline$L D_{A C, g, t}$ & Medium-skilled labor bundle of type $g$ \\
\hline$L D_{A C, l, t}$ & Low-skilled labor bundle of type $l$ \\
\hline$L D L_{A C, l f, t}$ & Local labor bundle of skill type $l f$ \\
\hline$M I G_{A C, l f, t}$ & Migrant labor of skill type $l f$ \\
\hline$L D L A_{a, l f, t}$ & Local labor of age $a$ and skill type $l f$ \\
\hline$E N R_{c, t}$ & Enrolled by educational cycle \\
\hline$G R A D_{c, t}$ & Graduates by educational cycle \\
\hline$N E W E N R_{e d u, t}$ & Newly enrolled in cycles voc or deg \\
\hline TOTNEWENRt & Newly enrolled in tertiary education \\
\hline$N E W E N R F I E L D_{l f, t}$ & Newly enrolled in tertiary education \\
\hline$a v f w_{l f, t}$ & Average wage of labor of skill type $l f$ \\
\hline$U r_{l f, t}$ & Unemployment rate of labor of skill type $l f$ \\
\hline$C A N D I D_{l f, t-n}$ & Succesfully accepted candidates by labor skill type \\
\hline$a v f w m_{l f, t}$ & Average wage of migrant labor of skill type $l f$ \\
\hline$S M I G_{l f, t}$ & Total migrant supply by skill type \\
\hline$I M M I G_{A C, l f, t}$ & Sectoral demand for migrant labor of skill type $l f$ \\
\hline$w f_{A C, l f, t}$ & Sectoral wage of local labor of skill type $l f$ \\
\hline af $w_{l f, t}$ & Average wage of local labor of skill type $l f$ \\
\hline
\end{tabular}


Table 8: Parameters used in the CGE model

\begin{tabular}{|c|c|}
\hline$A_{A C, t}$ & Labor Augmenting Productivity Parameter \\
\hline$\alpha_{A C, K}$ & Share parameter of capital \\
\hline$\alpha_{A C, L}$ & Share parameter of Labor \\
\hline$\alpha_{A C, H S}$ & Share parameter of high-skilled labor \\
\hline$\alpha_{A C, M S}$ & Share parameter of medium-skilled labor \\
\hline$\alpha_{A C, L S}$ & Share parameter of low-skilled labor \\
\hline$A_{H S, A C, t}$ & High-skilled labor productivity parameter \\
\hline$A_{M S, A C, t}$ & Medium-skilled labor productivity parameter \\
\hline$A_{L S, A C, t}$ & Low-skilled labor productivity parameter \\
\hline$\beta_{s}$ & Share parameter of high-skilled labor type $f$ \\
\hline$\beta_{g}$ & Share parameter of medium-skilled labor type $g$ \\
\hline$\beta_{l}$ & Share parameter of low-skilled labor type $l$ \\
\hline$\alpha_{A C, l o c, l f}$ & Share parameter of local labor \\
\hline$\alpha_{A C, m i g, l f}$ & Share parameter of migrant labor \\
\hline$\alpha_{y, l f}$ & Share parameter of young local labor \\
\hline$\alpha_{n y, l f}$ & Share parameter of older local labor \\
\hline dropout $_{c}$ & Dropout rate by educational cycle \\
\hline enrolled $_{c, t}$ & Enrolled by educational cycle (historical figure used in calculations) \\
\hline entrants $s_{t}$ & New entrantsl by educational cycle (historical figure used in calculations) \\
\hline $\operatorname{grad}_{c, t}$ & Graduates by educational cycle (historical figure used in calculations) \\
\hline $\operatorname{exdip}_{c}$ & Share of graduates pursuing further studies, by cycle \\
\hline transmap & Mapping parameter relating different educational cycles \\
\hline equiv $v_{c, c 2}$ & Equivalency parameter denoting cycles which are similar in the educational hierarchy \\
\hline gradrate $_{c}$ & Graduation rate, by cycle \\
\hline$\alpha_{v o c}$ & Share parameter of vocational students \\
\hline$\alpha_{d e g}$ & Share parameter of academic students \\
\hline$\gamma_{f}$ & Share parameter of field of study $f$ in academic degrees \\
\hline$\gamma_{g}$ & Share parameter of field of study $g$ in vocational degrees \\
\hline transage $_{l f}$ & Transition rate between age categories, by skill type \\
\hline edumap $_{c, l f}$ & Mapping parameter between educational cycles and labor skill types \\
\hline inact $_{l f}$ & Inactivity rate by skill type \\
\hline places $_{l f, t}$ & Number of places by field of study (tertiary cycles only) \\
\hline mort $_{l f}$ & Mortality rate by labor skill type \\
\hline retir $_{l f}$ & Retirement rate by labor skill type \\
\hline$w d o m_{l f, t}$ & Domestic country wage rate by skill type \\
\hline$\beta_{1, l f}$ & Wage curbe intercept parameter \\
\hline$\beta_{2, l f}$ & Wage curve elasticity parameter \\
\hline fwdist $_{A C, l f}$ & Exogenous sectoral wage differentials by skill type \\
\hline
\end{tabular}


Table 9: Elasticity parameters used in the CGE model

$\begin{array}{rr}\sigma_{1, A C} & \text { Elasticity of substitution between aggregate labor and aggregate capital } \\ \sigma_{2, A C} & \text { Elasticity of substitution between high-skilled, medium-skilled and low skille labor } \\ \sigma_{3, A C} & \text { Elasticity of substitution between high-skilled labor bundles } \\ \sigma_{4, A C} & \text { Elasticity of substitution between medium-skilled labor bundles } \\ \sigma_{5, A C} & \text { Elasticity of substitution between low-skilled labor bundles } \\ \sigma_{6, A C, l f} & \text { Elasticity of substitution between migrant and local labor } \\ \sigma_{7, A C} & \text { Elasticity of substitution between younger and older labor } \\ \sigma_{8, l f} & \text { Elasticity of transformation of migrant supply } \\ \sigma_{9, l f} & \text { Elasticity of transformation of migrants between sectors } \\ \sigma_{10, l f} & \text { Elasticity of transformation between vocational degrees } \\ \sigma_{11, l f} & \text { Elasticity of transformation between academic degrees } \\ \sigma_{12, l f} & \text { Elasticity of transformation between vocational and academic studies }\end{array}$

Figure 6: CET equations used to derive educational demands

$$
\begin{gathered}
\text { TOTNEWENR } R_{t}=\left[\alpha_{v o c} \times N E W E N R_{v o c, t}^{\rho_{10}}+\alpha_{d e g} \times N E W E N R_{d e g, t}^{\rho}\right]^{\frac{1}{\rho}} \\
N E W E N R_{v o c, t}=\left[\gamma_{g} \times \sum_{g} N E W E N R F I E L D_{g, t}^{\rho_{11}}\right]^{\frac{1}{\rho_{11}}} \\
N E W E N R_{d e g, t}=\left[\gamma_{f} \times \sum_{f} N E W E N R F I E L D_{f, t}^{\rho_{12}}\right]^{\frac{1}{\rho_{12}}}
\end{gathered}
$$


Table 10: Evolution of industry labor shares and proportion of skilled labor by industry, 19902011

\begin{tabular}{rrr}
\hline Industry & $\Delta$ (laborshare) & $\Delta$ (skillsshare $)$ \\
\hline Agriculture & $-13.6 \%$ & $2.1 \%$ \\
Oil \& Gas & $0.0 \%$ & $27.0 \%$ \\
Manufacturing food, beverages, tobacco & $-0.2 \%$ & $8.9 \%$ \\
Manufacturing textile & $-2.3 \%$ & $7.0 \%$ \\
Manufacturing wood & $-0.4 \%$ & $2.7 \%$ \\
Manufacturing paper \& furniture & $0.4 \%$ & $10.7 \%$ \\
Manufacturing chemicals rubber & $0.4 \%$ & $16.2 \%$ \\
Metals, machinery, equipment NEC & $-0.1 \%$ & $12.3 \%$ \\
Electronics \& electrical & $4.1 \%$ & $16.5 \%$ \\
Manufacturing \& transport equipment & $0.4 \%$ & $16.0 \%$ \\
Utilities & $-1.5 \%$ & $23.2 \%$ \\
Construction & $2.9 \%$ & $11.2 \%$ \\
Wholesale \& retail & $2.1 \%$ & $10.3 \%$ \\
Accommodation \& restaurants & $2.1 \%$ & $6.3 \%$ \\
Logistics & $1.4 \%$ & $11.7 \%$ \\
Post and telecom & $0.9 \%$ & $59.6 \%$ \\
Finance & $0.7 \%$ & $33.7 \%$ \\
Real estate & $0.2 \%$ & $30.6 \%$ \\
Business services & $3.8 \%$ & $15.8 \%$ \\
Education & $0.7 \%$ & $20.9 \%$ \\
Health & $0.9 \%$ & $44.0 \%$ \\
Other services & $-2.3 \%$ & $6.8 \%$ \\
Public administration & $-0.6 \%$ & $23.0 \%$ \\
\hline
\end{tabular}


Figure 7: Evolution of wages of low-skilled malaysians without SBTC

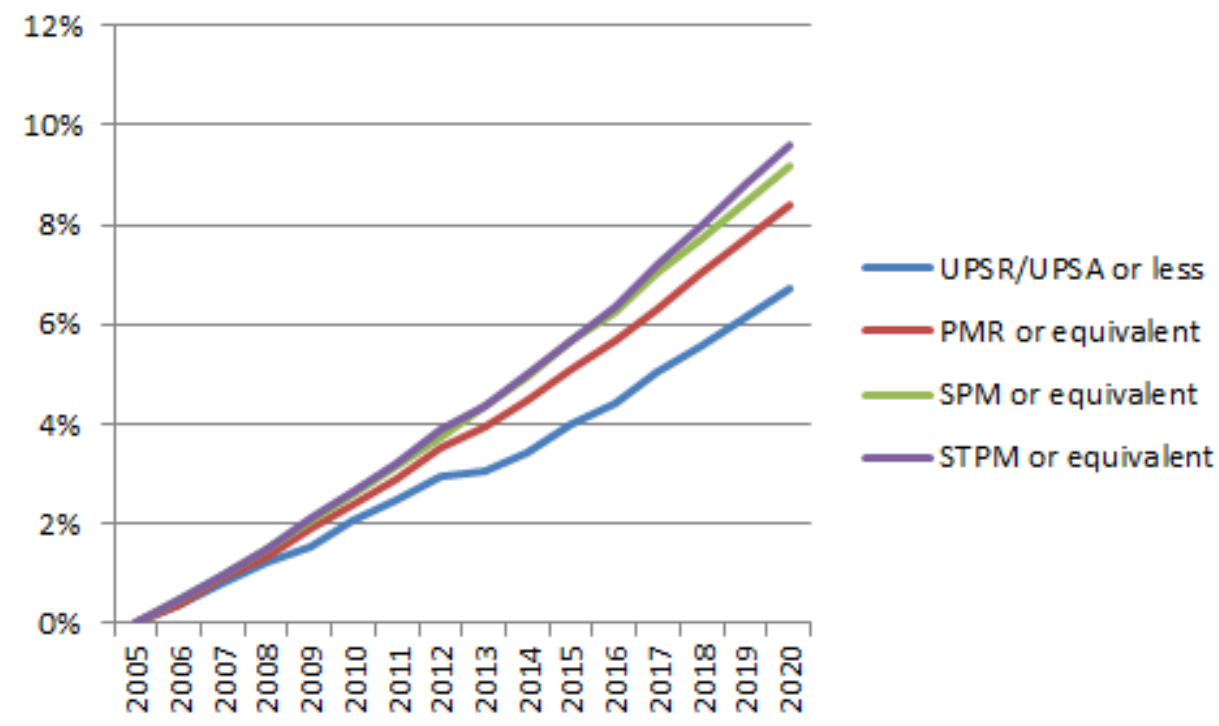

Figure 8: Evolution of wages of diploma holders without SBTC

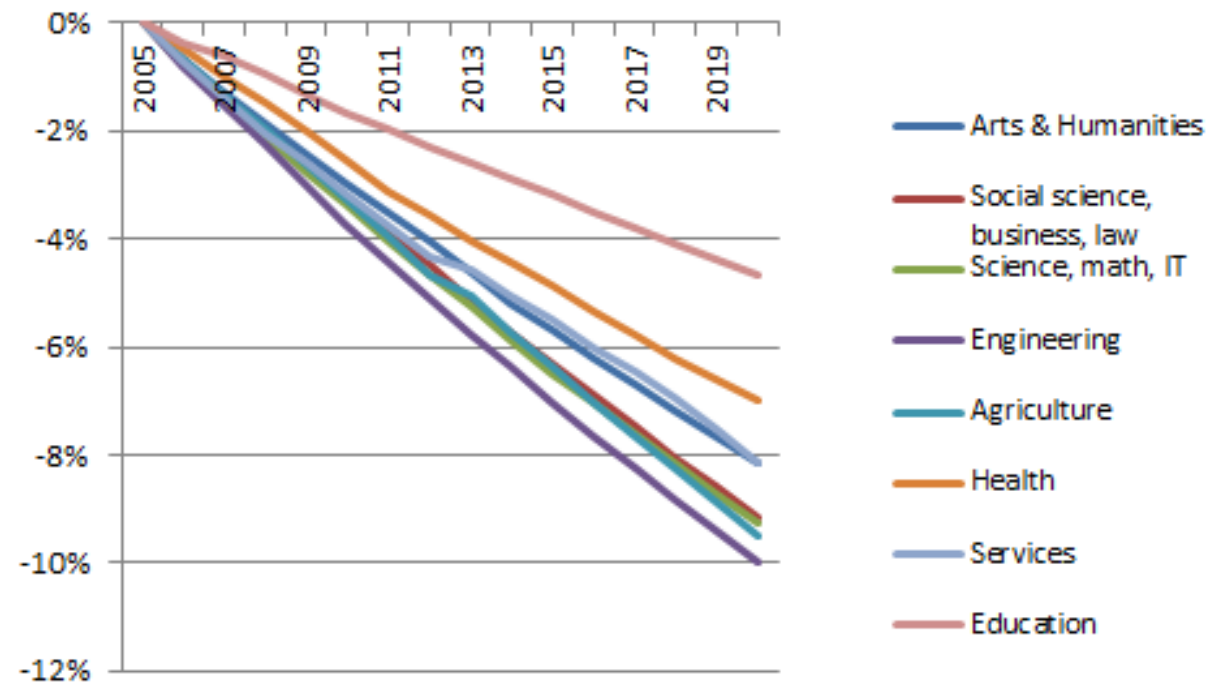


Figure 9: Evolution of wages of degree holders without SBTC

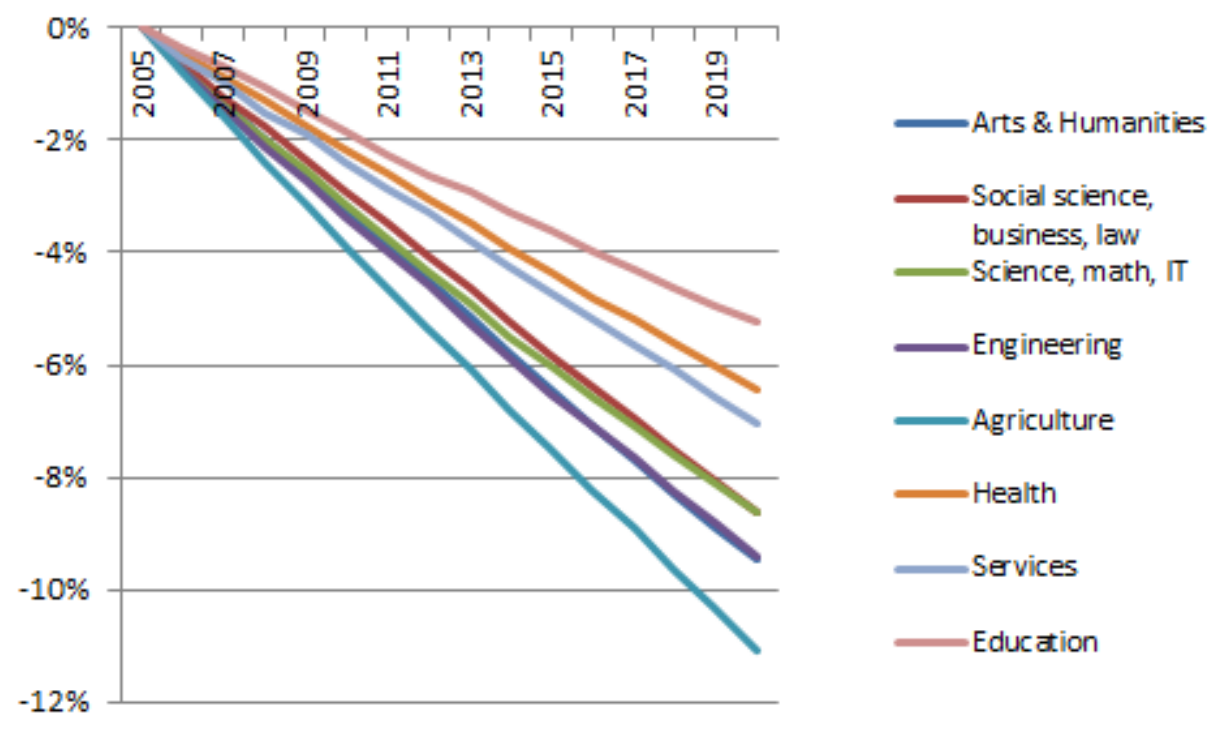

Figure 10: Evolution of selected wage differentials without SBTC

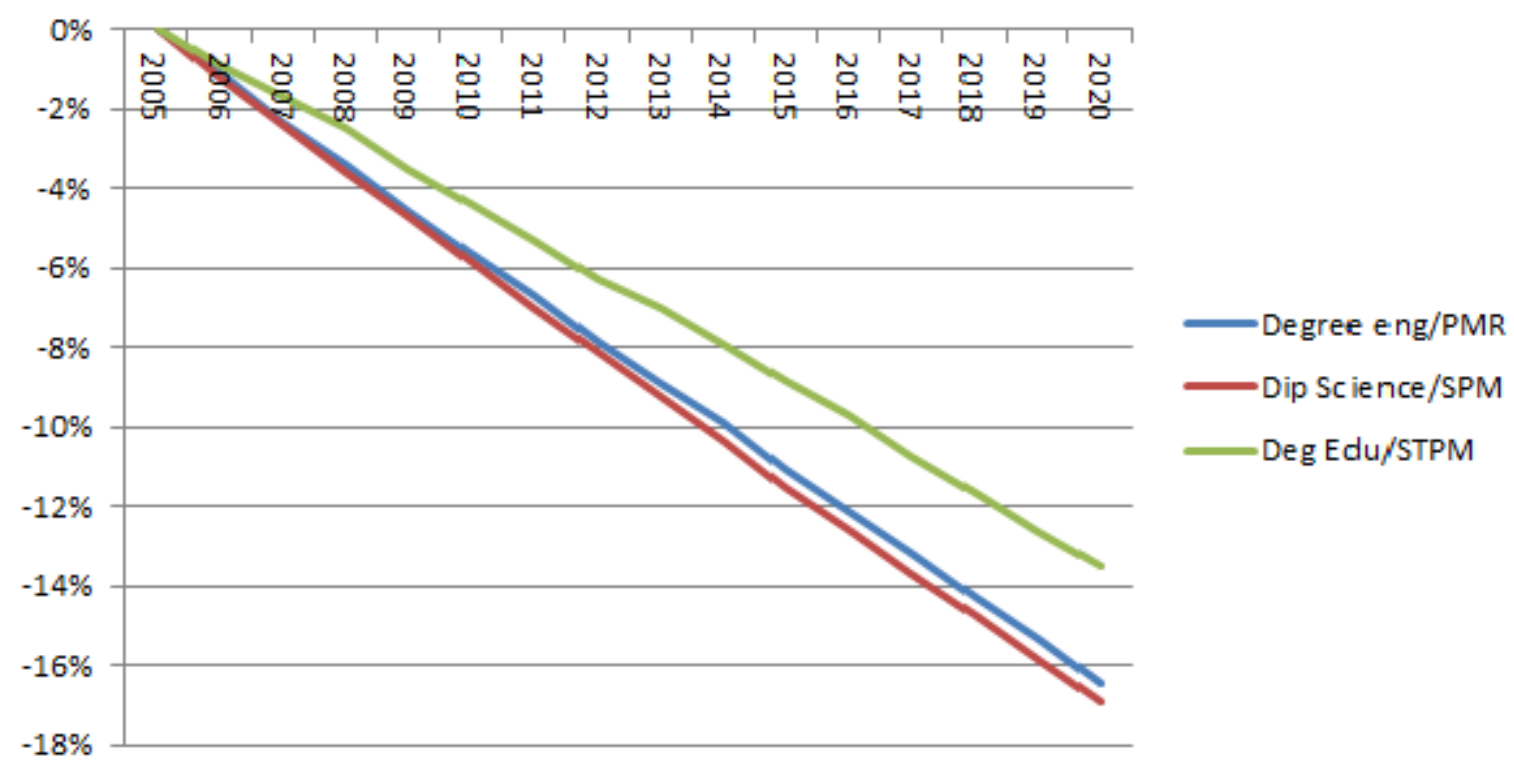


Figure 11: Evolution of unemployment of diploma holding wage earners with rationing

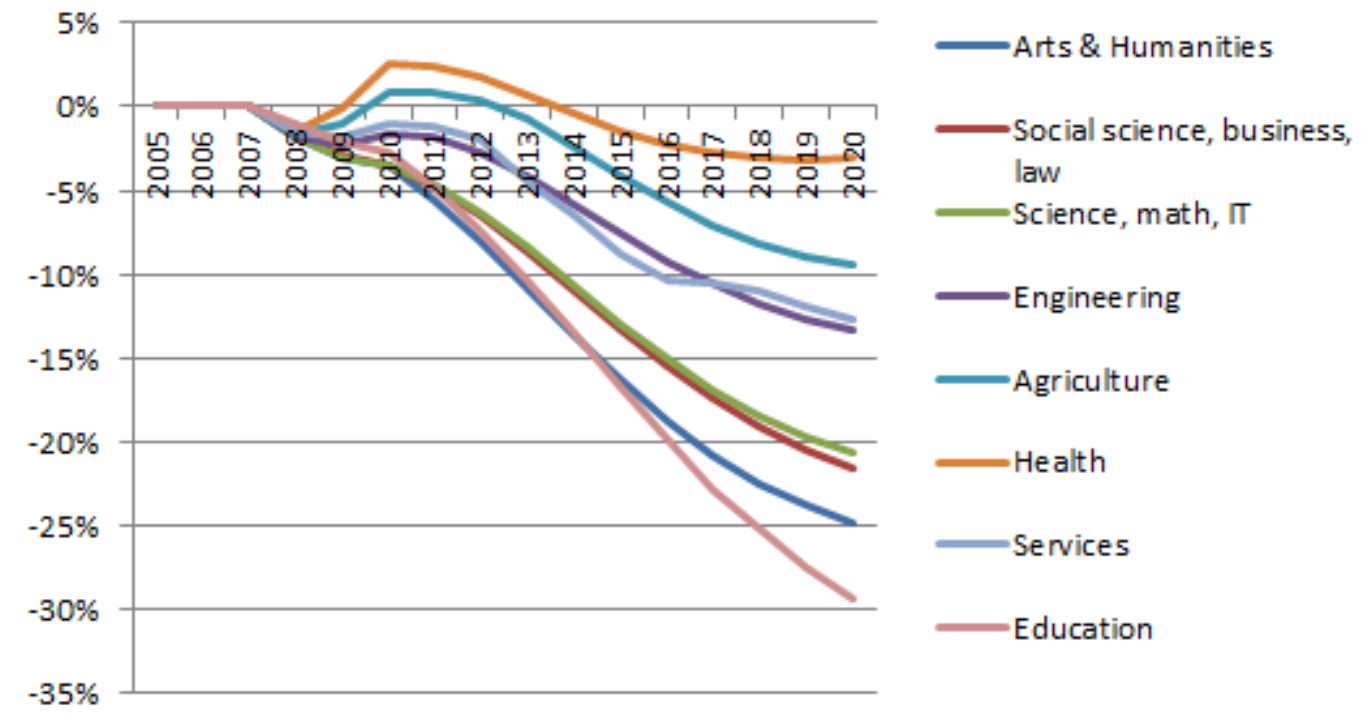

Figure 12: Evolution of wages of diploma holders with rationing
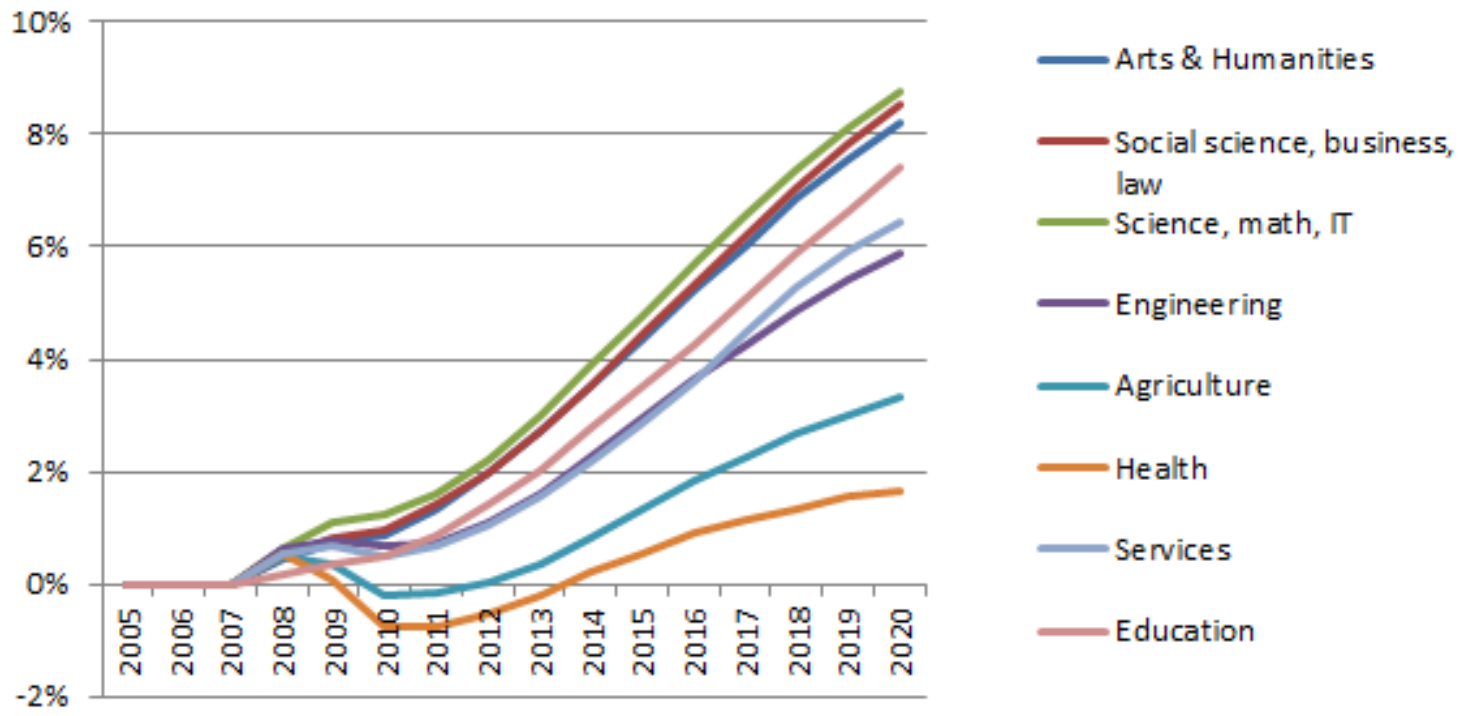
Figure 13: Evolution of wages of degree holders with rationing

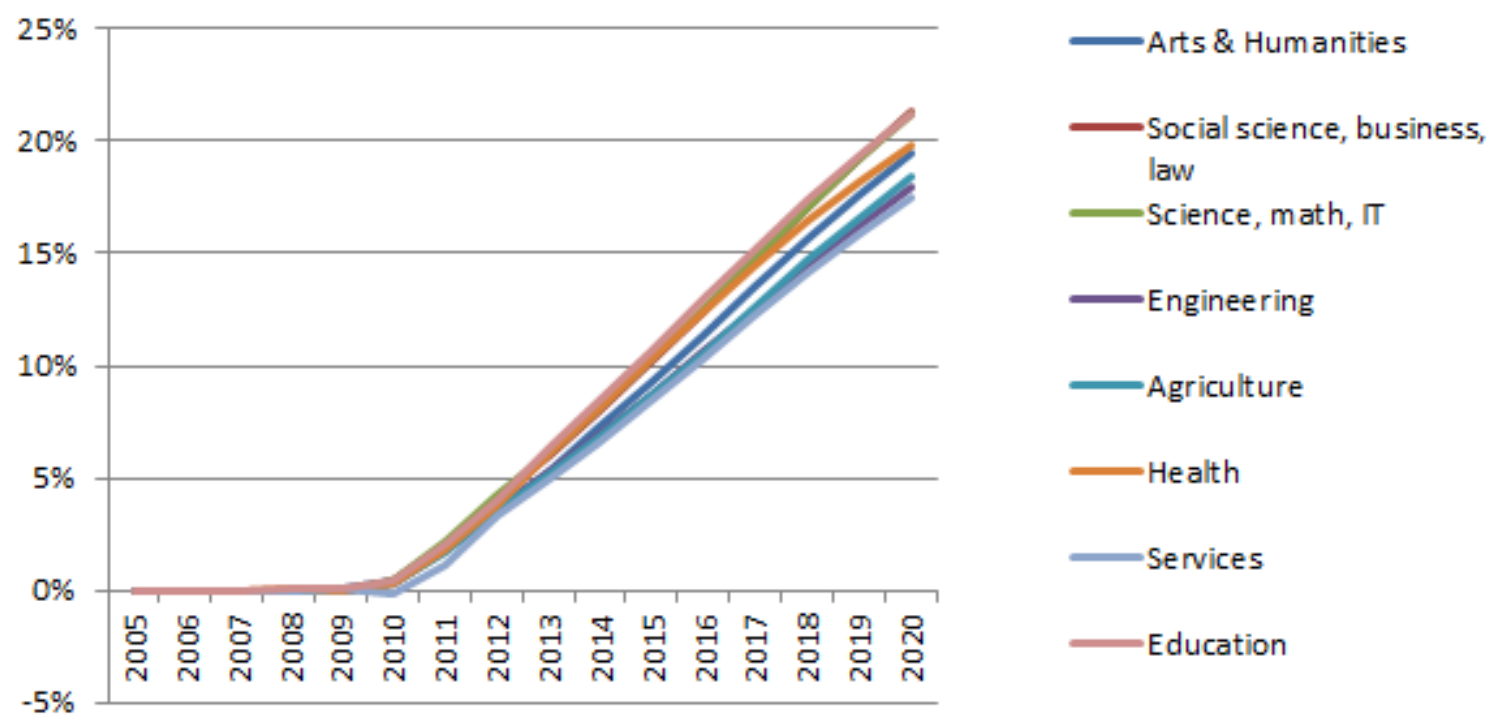

Figure 14: Evolution of selected wage differentials with rationing

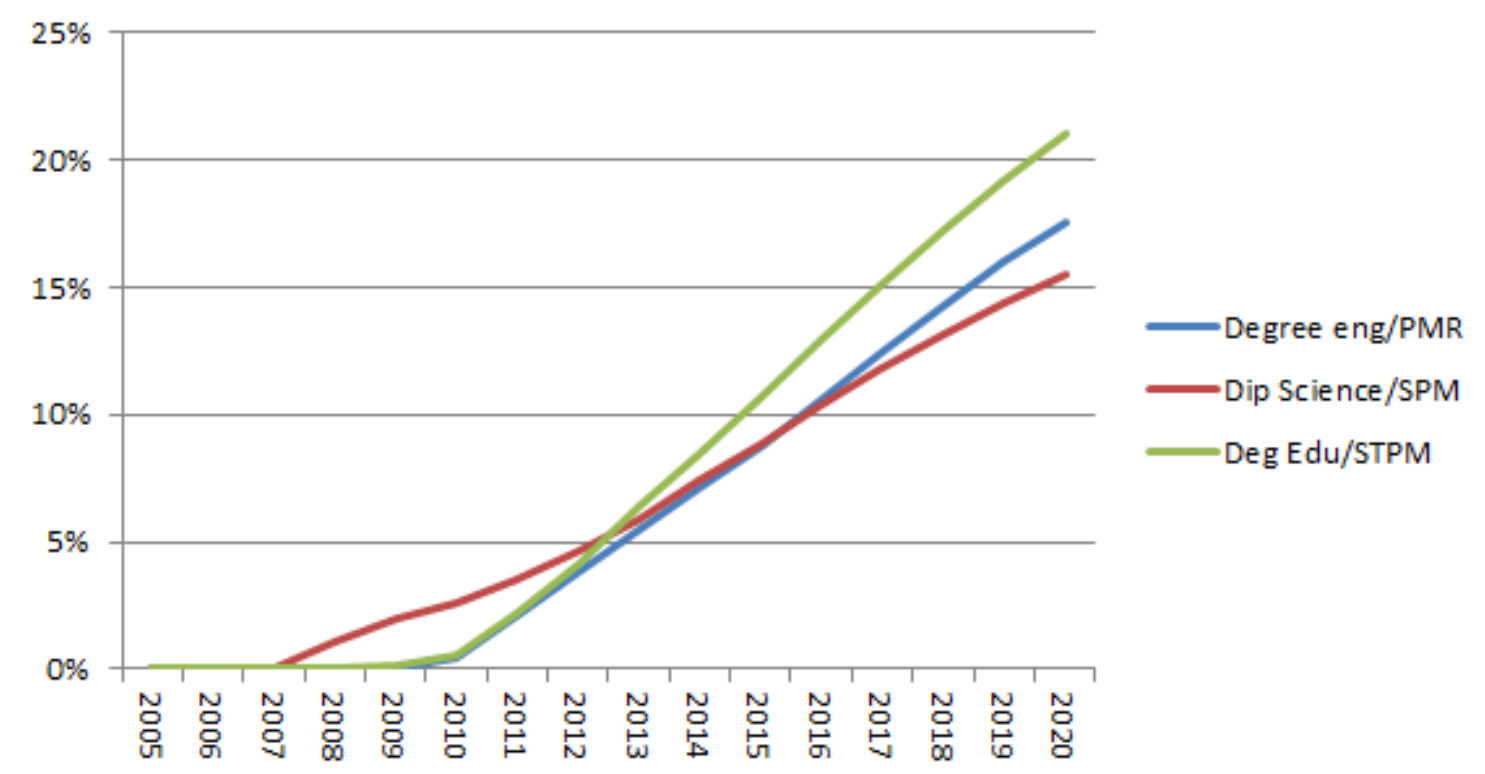


Figure 15: Evolution of degree holders' wages without SBTC (4\%) for various elasticities of substitution

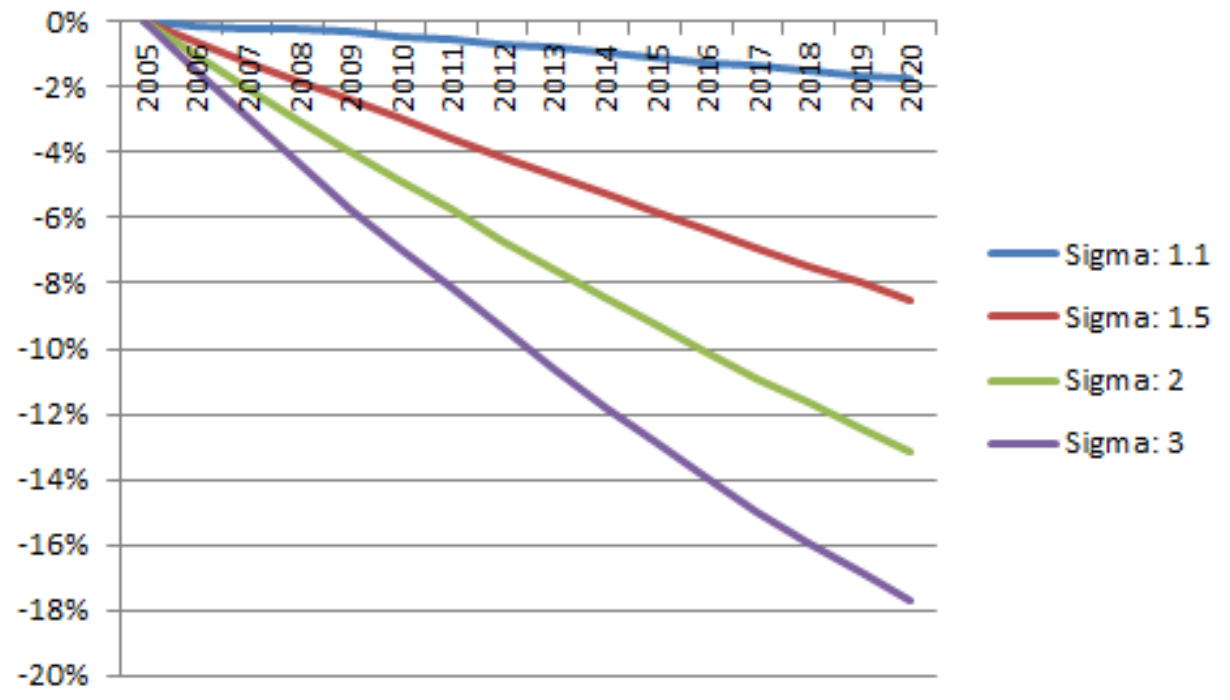

Figure 16: Evolution of wages of less skilled workers without SBTC (4\%) for various elasticities of substitution

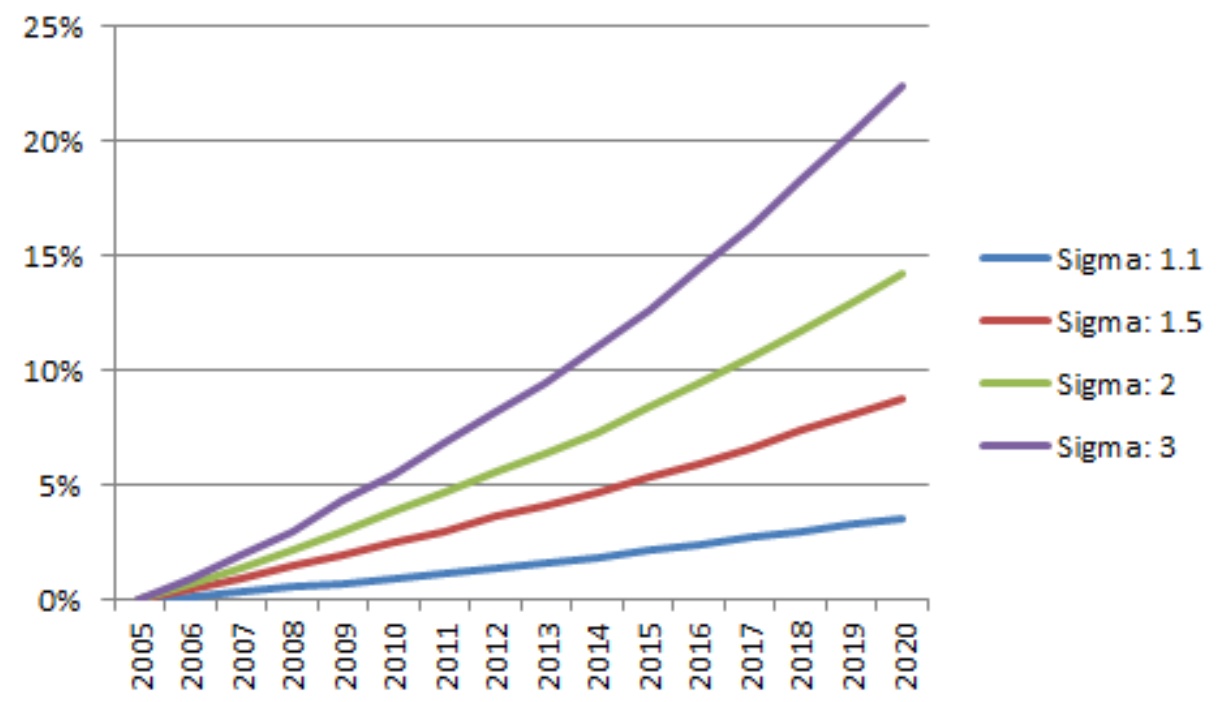


Figure 17: Evolution of degree holders' wages for various levels of SBTC (Sigma: 1.5)

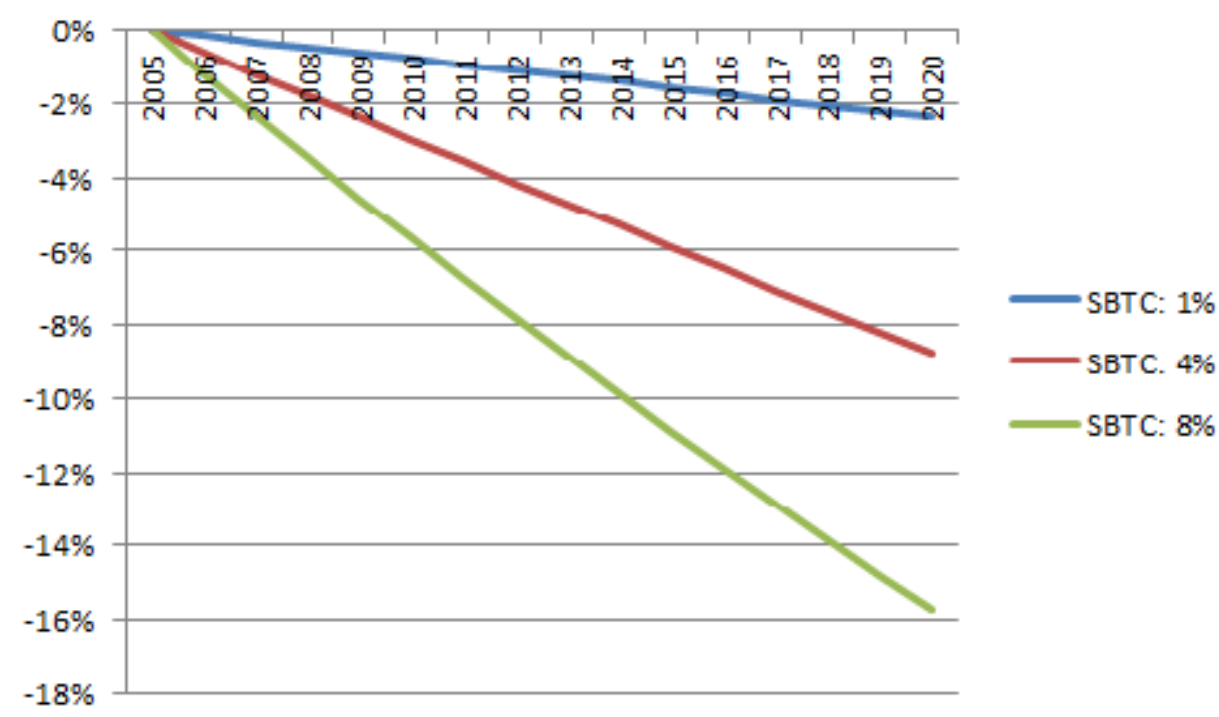

Figure 18: Evolution of wages of less skilled workers for various levels of SBTC (Sigma: 1.5)

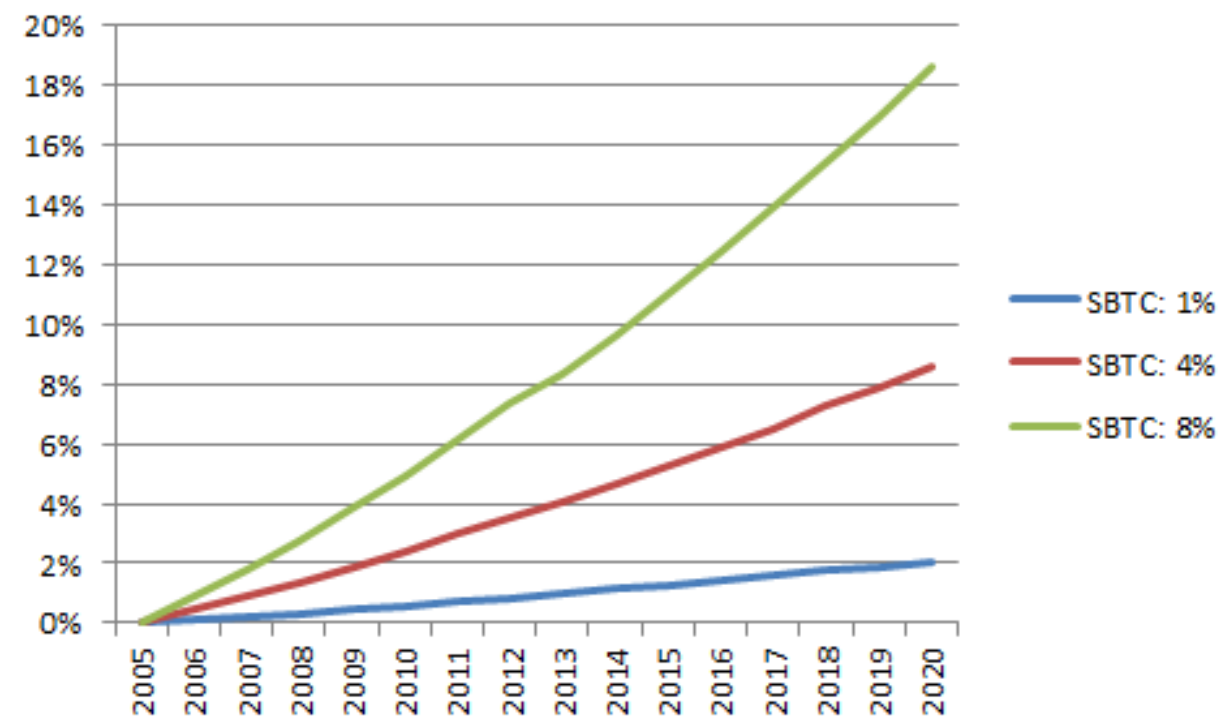

